Syracuse University

SURFACE

Dissertations - ALL

SURFACE

August 2019

\title{
Vicarious Racial Discrimination, Racial Identity, and Alcohol- Related Outcomes among Black Young Adults: An Experimental Approach
}

Jessica Mae Desalu

Syracuse University

Follow this and additional works at: https://surface.syr.edu/etd

Part of the Social and Behavioral Sciences Commons

\section{Recommended Citation}

Desalu, Jessica Mae, "Vicarious Racial Discrimination, Racial Identity, and Alcohol-Related Outcomes among Black Young Adults: An Experimental Approach" (2019). Dissertations - ALL. 1098.

https://surface.syr.edu/etd/1098

This Dissertation is brought to you for free and open access by the SURFACE at SURFACE. It has been accepted for inclusion in Dissertations - ALL by an authorized administrator of SURFACE. For more information, please contact surface@syr.edu. 


\begin{abstract}
Personal experiences of racial discrimination have been well investigated for its association with diverse alcohol-related outcomes among Black Americans. However, vicarious racial discrimination (i.e., the observation of others' experience of racial discrimination) has yet to be examined for its alcohol-related outcomes. The extent to which vicarious discrimination experiences influence alcohol outcomes may differ by three components of racial identity: centrality (significance of being Black), private regard (personal evaluative judgments of being Black), and public regard (beliefs about others' evaluative judgments of Blacks). The current within-subject experiment examined whether associations of vicarious racial discrimination (manipulated by video clips) with alcohol use craving and alcohol attentional bias differed by racial identity among Black young adults. Ancillary analyses explored whether negative affect in response to vicarious racism exposures mediated the interaction between vicarious racism and racial identity. Fifty-one Black young adult at-risk drinkers (mean age $=21$ years $[S D=3.02] ; 60 \%$ female) completed mild and extreme vicarious racism conditions and tasks to assess alcohol craving and alcohol attentional bias in random orders. High private regard buffered effects of vicarious racial discrimination on alcohol craving, while high centrality exacerbated its effects, after accounting for sex, social desirability, and frequencies of binge drinking and racial discrimination. No moderating role of public regard was found. Further, negative affect did not mediate the interaction between vicarious racism and any of the racial identity components. Current findings shed light on the role of vicarious racism in alcohol outcomes of Black young adults and sub-groups of Blacks at risk for adverse alcohol outcomes based on racial identity. Keywords: vicarious racial discrimination, alcohol craving, alcohol attentional bias, Black young adults, racial identity
\end{abstract}


VICARIOUS RACIAL DISCRIMINATION, RACIAL IDENTITY, AND ALCOHOLRELATED OUTCOMES AMONG BLACK YOUNG ADULTS: AN EXPERIMENTAL APPROACH

by

Jessica M. Desalu

B.S., Howard University, 2013

M.S., Syracuse University, 2014

\begin{abstract}
Dissertation
Submitted in partial fulfillment of the requirements for the degree of Doctor of Philosophy in Clinical Psychology
\end{abstract}

Syracuse University

August 2019 
Copyright $@$ Jessica M. Desalu 2019

All Rights Reserved 


\section{Acknowledgments}

God: You are too good to me. You called me to this journey and your grace and mercy have gotten me through. When I've pulled away, You have remained close-thank you.

Philippians 3:12-14

The Desalu Family: This moment would not be possible without each one of you. No words can truly capture my gratitude; I hope that I have made you all proud - this one is for US. I would like to especially thank my mother-mommy, your strength and love have been my fuel. And to my niece Krisanally_your love and awe of me, as well as your own resilience, has propelled me forward in ways that you don't even know. Because of you, I seek to be a better me.

Friends: I would like to thank the young women who have remained by my side no matter what. Your ears have been my safe haven; your spirts have been my light in dark times. Ashley, Tamika, Chloe, Seneca, Jasmine, Patrice, and Chantelle...from the depths of my heart, thank you. Syracuse: Thank you to my lab-mates, my dedicated all female research team for making this project possible, and my academic advisor. Dr. Park, the journey has been long; thank you for pushing me beyond mediocrity. You have no idea the extent to which you have shaped my life. Howard University: You have given me way more than just academics. You have given me strength, an anchored sense of Black pride, HUCS, great friends, and a great partner. No matter where I go, I will forever shout: HU, You Know!

Black Lives Matter: Finally, I would like to acknowledge the many Black men and women who have become victims of racial discrimination and brutality. May your names and stories never be forgotten. With this project, my hope is that I have turned at least the slightest bit of pain into purpose.

"They say that dreams come true and when they do, that there's a beautiful thing"-J. Cole 
Table of Contents

Page

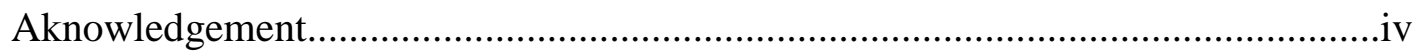

Table of Contents .......................................................................................

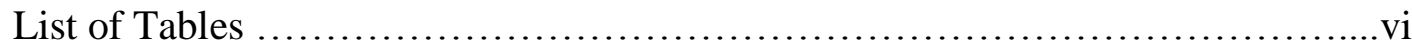

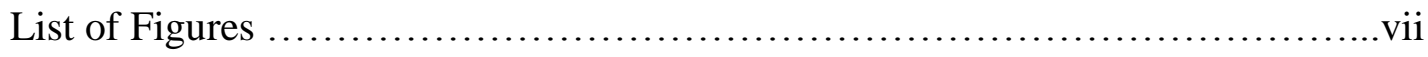

Chapter

I. Introduction........................................................................................ 1

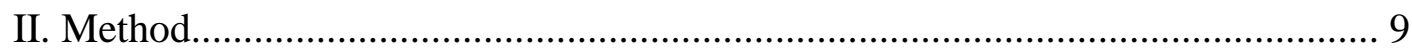

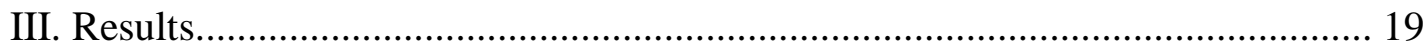

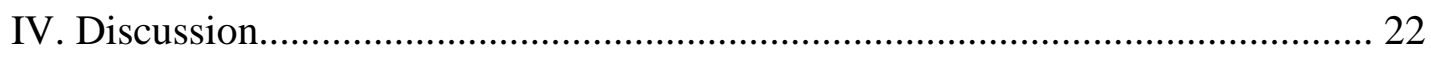

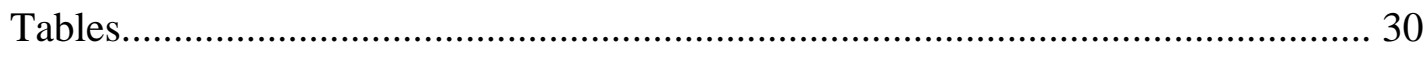

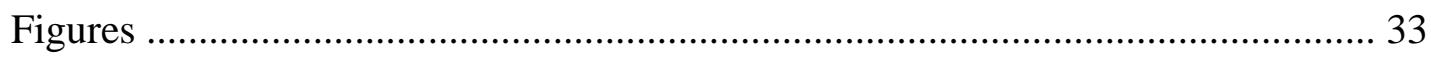

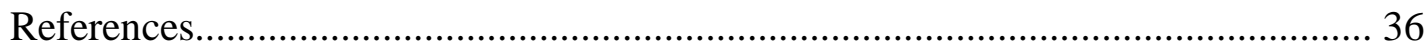

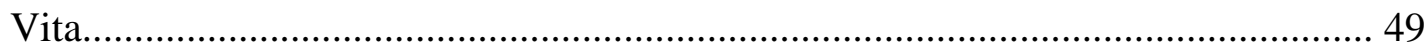




\section{List of Tables}

Tables Page

1. Correlation Coefficients of Study Variables................................ 30

2. Mean Comparisons of Study Variables as a Function of Video Conditions..........31

3. Mixed ANOVA Analyses Examining Interaction Effects of Racial Identity and

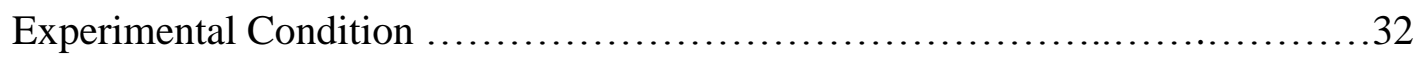


List of Figures

Figures

Page

1. Theoretical Framework of the Multidimensional Conceptualization for RacismRelated Stress ...................................................... 33

2. Experimental protocol.............................................. 34

3. Estimated marginal means of alcohol use craving in mild and extreme vicarious racial discrimination experimental conditions as a function of racial centrality and private regard levels (i.e., one SD below the mean, the mean, and one SD above the

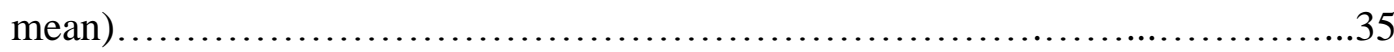


Vicarious Racial Discrimination, Racial Identity, and Alcohol-Related Outcomes among Black Young Adults: An Experimental Approach

Young adulthood is a period of high-risk alcohol use and associated consequences among Black individuals in the U.S. Prevalence rates of past-year alcohol use among Black individuals drastically increase from $17 \%$ at ages 12 to 17 to $69 \%$ at ages 18 to 25 (National Survey on Drug Use and Health [NSDUH], 2016). Although past-month binge drinking (defined as five or more drinks for men or four or more drinks for women in a single setting) decreases during the transition to young adulthood on average across racial groups (39\% to 25\%), comparable "maturing out" effects are less salient for Black young adults specifically (30\% to 25\%; NSDUH, 2016). Furthermore, despite equivalent or lower levels of alcohol use, the rate of negative drinking consequences (e.g., social consequences such as fights/arguments, legal consequences, alcohol dependence symptoms) for Blacks exceeds that of their other racial counterparts in young adulthood (Clarke et al., 2013; Zemore et al., 2016). Thus, although Blacks drink less heavily than other racial groups on average, their drinking behaviors accelerate faster, are more stable across adulthood, and result in relatively greater consequences. Continued research is needed to identify racially-relevant risk and protective factors of this alcohol-related disparity among Black Americans.

\section{Racial Discrimination and Alcohol Behaviors}

Racial discrimination has been identified as an important racially relevant risk factor for alcohol-related outcomes among Black Americans (Clark, Anderson, Clark, \& Williams, 1999; Harrell, 2002). Racial discrimination is defined as perceived and/or internalized beliefs, attitudes, institutional arrangements, and acts that denigrate Americans because of their racial group (Clark et al., 1999). Various forms of racial discrimination may contribute to the alcohol-related outcomes of Black young adults. Specifically, the "Multidimensional Conceptualization of Racism-Related Stress" (Harrell, 2002) framework highlights the 
presence of diverse forms of racial discrimination experiences that lead to adverse health behaviors and outcomes, including vicarious racial discrimination (also referred to as vicarious racism or vicarious discrimination). This framework also seeks to delineate various psychosocial factors (e.g., racial identity) that may modify the association between racial discrimination and adverse health behaviors and outcomes (i.e., moderators). Moreover, the framework proposes possible mechanisms (i.e., mediators) underlying associations of discrimination with maladaptive coping. For example, heightened affective responses (e.g., sadness, anger) are theorized to occur subsequent to the exposure of diverse forms of racial discrimination, which in turn increase the likelihood of maladaptive coping behaviors such as alcohol use. Although research has begun providing support for the various tenets of this Racism-Related Stress model (see reviews by Paradies, 2006; Pieterse, Todd, Neville, \& Carter, 2012), the potential role of vicarious racial discrimination has not been well investigated.

\section{Vicarious Racial Discrimination}

Racism exerts its influence not only through direct personal experience but also vicariously through first-hand accounts or narrative reports (e.g., via conversations, social media, news coverage, etc.) of others' experiences with racism; this is known as vicarious racial discrimination (Harrell, 2002). Unjust racial treatment is not a new phenomenon in the Black community; however, with the widespread use of smartphones and social media, individuals can now easily document and rapidly disseminate graphic images of discriminatory events (Cooper \& Fullilove, 2016), making it increasingly important to study the role of vicarious racial discrimination. Yet, the literature on vicarious racial discrimination is nascent with only a few studies focusing on its prevalence among Blacks. In a cross-sectional study of Black young adults, $78 \%$ had heard about someone of their race getting injured or killed because of a racism-related event and $67 \%$ had viewed someone 
being the target of racial maltreatment (Waelde et al., 2010). Similarly, in a qualitative study of Black adult women, vicarious racial discrimination emerged as one of the most salient experiences of racism (Nuru-Jeter et al., 2009). For example, women discussed becoming aware of instances in which their children were referred to by a racial slur and provided commentary on its impact on them personally (e.g., "I go through the hurt when [my children] go through the hurt"). Over and above that, news coverage in the United States and social media outlets are regularly filled with images of Black individuals who have been killed or injured in encounters that are either clearly or possibly racially-motivated (Alvarez \& Blinder, 2015; Rankine, 2015).

Empirical research, however, is limited on how the observation of others' experiences with discrimination influences health outcomes of Blacks. An experimental study of college students showed that, when Black students were exposed to photos of victims of high-profile incidences of police brutality against Black individuals (e.g., Eric Garner), they reported greater negative affective and physiological reactivity (Kort, 2016). Likewise, when exposed to a racist film clip, Black men showed greater blood pressure reactivity and anger, compared to those exposed to a neutral non-racist film clip (Fang \& Myers, 2001). However, to date, the association between vicarious racial discrimination and alcohol outcomes has not been empirically investigated.

\section{Literature Gaps in the Racial Discrimination-Alcohol Outcome Literature}

Several gaps remain in the literature on racial discrimination and alcohol outcomes among Black individuals. First, studies investigating variability within Black individuals (versus comparisons across racial groups) are relatively lacking. Thus far, racial comparisons of alcohol-related outcomes and their risk and protective factors have been the primary focus of most empirical research. Although racial comparative research offers knowledge regarding health disparities and their correlates across diverse populations, it is insufficient to advance 
our understanding of within-group variability and identify sub-groups of Black young adults that may be at a greater risk for alcohol use and related consequences (Whitfield, Allaire, Belue, \& Edwards, 2008). The association between racial discrimination and alcohol-related behaviors has been consistently shown to be stronger among Blacks than among other racial counterparts (Borrell et al., 2010; Borrell et al., 2013; Zemore, Karriker-Jaffe, Keithly, \& Mulia, 2011). However, findings from individual studies of the association are largely mixed when assessing all-Black samples (as opposed to mixed racial samples), with some studies reporting positive associations (Borrell et al., 2010; Thompson, Goodman, \& Kwate, 2016) and others reporting null results (Caldwell et al., 2013; Respress et al., 2013). Our recent meta-analytic review of studies using exclusively Black samples clarified the literature by demonstrating that racial discrimination was associated with various alcohol-related outcomes including heavy/binge drinking, at-risk drinking (as assessed by alcohol screeners such as CAGE, AUDIT-C), and negative drinking consequences (Desalu, Goodhines, \& Park, 2019). However, most studies included in the meta-analytic review investigated the association of perceived personal accounts of racial discrimination, apart from one study that assessed internalized racism (i.e., the acceptance of negative attitudes and beliefs perpetuated by the dominant society). The current study sought to reconcile this gap in the literature by investigating the extent to which vicarious experiences of racial discrimination are associated with alcohol-related outcomes within Black young adult drinkers.

Another important gap in the literature is the heavy reliance on observational studies (Desalu, Goodhines, \& Park, 2019). Observational studies are limited in their ability to determine causality due to their correlational nature. In addition, self-reported alcohol use may be unreliable due to recall bias (Davis, Thake, \& Vilhena, 2010) or cultural stigma associated with alcohol use among Black individuals (Zapolski et al., 2013). Experimental studies may reduce issues relating to recall bias of alcohol outcomes by use of implicit (i.e., 
attentional bias) and subjective craving measures of alcohol; such measures have been shown to correlate with actual alcohol use behaviors among racially diverse samples (e.g., Dennhardt \& Murphy, 2011; Kvamme et al., 2018; MacKillop et al., 2010). Moreover, an experimental design offers the opportunity to assess immediate reactions following exposure to racial discrimination (Williams \& Mohammed, 2009). Findings from two experimental studies showed that exposure to racial discrimination has detrimental effects on substance use but only among a certain subgroup of Black young adults. Specifically, an experimental study of Black college students demonstrated that, after being excluded due to race, individuals with low private regard of Black racial identity (i.e., feeling negatively about their Black racial status) displayed greater levels of automatic activation of alcohol-related thoughts (as assessed by reaction time in an alcohol-related lexical task; Richman et al., 2013). Likewise, Gerrard and colleagues (2012) found that when excluded from a game due to race, Black young adults endorsing high levels of substance use as a coping method displayed a greater willingness to use alcohol and drugs in hypothetical scenarios (e.g., being offered alcohol/drugs at a party). However, to date, vicarious racial discrimination has not yet been examined for its impact on alcohol outcomes using an experimental design.

\section{Racial Identity as a Moderator of Vicarious Racial Discrimination}

Racial identity may help explain individual differences in associations of discrimination experiences with negative health outcomes, including alcohol use. Racial identity is defined as the significance and meaning that one attributes to being of their racial group and has been conceptualized as having three significant components (Sellers, Smith, Shelton, Rowley, \& Chavous, 1998): centrality (i.e., the extent to which a person normatively defines themselves with regard to race), private regard (i.e., extent to which individuals feel positively or negatively about their racial status), and public regard (i.e., extent to which one feels that others view individuals of their race positively or negatively). However, there have 
been conflicting theoretical views and mixed empirical findings on the role of racial identity as a protective factor buffering the effects of racial discrimination versus a risk factor intensifying the effects of discrimination as described in detail below.

Feeling connected to one's racial group (i.e., strong racial centrality) is believed to compensate for the negative effects of discrimination, thereby buffering its detrimental effects. That is, in the presence of discrimination, individuals may be less negatively impacted by a discriminatory incident by focusing on the positive aspects of their racial group (i.e., high private regard; Sellers \& Shelton, 2003). In addition, the more one identifies with their racial group (i.e., high centrality), the more likely they may be to make attributions to discrimination and subsequently prepare themselves to implement effective coping responses (Salvatore \& Shelton, 2007). Finally, Black individuals who believe that other racial groups have relatively negative opinions of Blacks (i.e., low public regard) may be less affected by racial discrimination because it is consistent with their worldview (Sellers \& Shelton, 2003). Indeed, protective effects of racial identity have been observed in the broader racial discrimination literature. For example, Black young adults with high private regard reported experiencing less instances of daily racial discrimination (Burrow \& Ong, 2010); individuals who value being Black may spend more time in environments that foster racial pride and acceptance, thereby shielding them from exposure to racial discrimination. Likewise, higher racial centrality predicted lower levels of stress and psychological distress subsequent to racial discrimination exposure (Sellers, Caldwell, Schmeelk-Cone, \& Zimmerman, 2003). Taken together, these findings suggest that racial identity (specifically, high private regard and high centrality) can serve as a psychological buffer against the adverse effects of racial discrimination.

However, when one's race is a central component of an individual's identity, it is also possible that having a strong racial identity may exacerbate the effects of discrimination, 
resulting in poor health outcomes. Indeed, several researchers have theorized that, when individuals have race as a more central aspect of their self-concept, race-related stressors are likely to be more damaging; that is, threats to one's social group are perceived as threats to oneself (McCoy \& Major, 2003; Yip et al., 2008). Empirical findings indicate that individuals with stronger racial identities are more likely to report not only discrimination but also negative affect in response to discrimination. For example, several studies evidenced that young adults high in centrality reported more racially discriminatory events, as well as symptoms of depression and negative affect following racial discrimination in comparison to those low in centrality (Burrow \& Ong, 2010; McCoy \& Major, 2003; Neblett, Shelton, \& Sellers, 2004; Sellers et al., 2003). Similarly, Sellers and Shelton (2003) found that Black college students high in public regard showed greater negative emotional reactivity to racial discrimination. Taken together, racial identity (specifically, high centrality and high public regard) can indeed heighten the effects of racial discrimination.

Pertaining to alcohol/substance use behaviors, various aspects of racial identity have been most commonly studied as a protective factor (Caldwell, Sellers, Bernat, \& Zimmerman, 2004; Fuller-Rowell et al., 2012; Richman et al., 2013; Stock, Gibbons, Walsh, Gerrard, 2011; Stock et al., 2013). For example, in a longitudinal study of Black high school students, racial discrimination was less strongly associated with increases in substance use for individuals with lower levels of public regard than those with higher levels (Fuller-Rowell et al., 2012). Similarly, as previously mentioned, in an experimental study of Black college students, when exposed to racial discrimination, those with low private regard demonstrated faster response times to alcohol-related words in a lexical decision task and thus greater attention to alcoholrelated cues in comparison to those with high private regard. Of note, the role of racial centrality in the association between racial discrimination and alcohol/substance use has not 
been demonstrated, although there are studies that reported null findings (e.g., Caldwell et al., 2004; Fuller-Rowell et al., 2012).

\section{Underlying Mechanisms-Ancillary Exploration}

Associations between racial discrimination and alcohol behaviors may be explained by the experience of negative affective states (i.e., affective stress response). A central tenet of Harrell's Racism-Related Stress model, and of various theoretical models of drinking (e.g., tension-reduction and self-medication models; for a review, see Greeley and Oei 1999), suggest that people experience negative affect (e.g., depression, anxiety, and anger) as a result of the exposure to stressors (e.g., racism) and subsequently drink alcohol to alleviate negative affect. Alcohol drinking behavior is thought to be reinforced by its stress-dampening effects. Indeed, it has been shown that a primary reason that Black young adults drink is to regulate negative emotions (Cooper et al., 2008). Moreover, both anger and depressive symptoms (Boynton et al., 2014) have been shown to underlie the relationship between selfreported racial discrimination and alcohol-related problems among Black college students. Likewise, Desalu and colleagues (2017) found empirical evidence for sequential mediators of depressive symptoms and coping motives underlying the discrimination-alcohol relationship among Black college drinkers. Notably, all the aforementioned studies were of crosssectional designs; thus, though they provide initial insight into possible mechanisms, a chain of causality cannot be determined. Further investigation into the processes by which racial discrimination, specifically vicarious racial discrimination, impacts alcohol-related outcomes among Blacks using an experimental design is warranted to add clarity to the limited knowledge about underlying affective processes.

\section{Goals of the Current Study}

Using a within-subject experimental study design, the current study examined: (a) whether vicarious racial discrimination was associated with self-reported alcohol use craving 
and attentional bias to alcohol cues and (b) whether these associations differed by three aspects of racial identity (i.e., centrality, private regard, public regard). Ancillary analysis also explored whether negative affect mediated the aforementioned moderation associations (i.e., mediated moderation). Following two vicarious racial discrimination video conditions (i.e., Mild and Extreme racism), risky-drinking Black young adults completed two alcoholrelated tasks in a randomized order: self-report alcohol use craving in response to the exposure to in-vivo alcohol cues and an implicit alcohol-related task (i.e., attentional alcohol bias). It was hypothesized that, following exposure to Extreme (versus Mild) vicarious racial discrimination, individuals will show greater alcohol craving and faster response times to alcohol-related cues on the implicit task. Additionally, regarding three aspects of racial identity, it was hypothesized that higher private regard and lower public regard would buffer the negative effects of exposure to vicarious racism on alcohol outcomes; a specific hypothesis regarding centrality was not denoted given the mixed and null findings of prior research on its moderating effects of alcohol use. Finally, it was hypothesized that the aforementioned moderation of vicarious racism and racial identity will be explained by negative affect in response to vicarious racial discrimination.

\section{Method}

\section{Participants}

Participants were 51 young adult at-risk drinkers of African descent (i.e., Black) aged between 18 and 30 (mean age $=21$ years $[S D=3.02]$; 60\% female). Young adults were recruited because this developmental period is characterized by accelerated problematic alcohol use for Black Americans, considering that alcohol use behaviors peaks later and persists longer through adulthood for Blacks (Cooper et al., 2008; Muthen \& Muthen, 2000). At-risk drinkers (defined as those who engage in drinking that exceed recommended limits and increases a person's risk of alcohol-related problems; Dawson, 2011) were recruited due 
to their higher level of alcohol cue reactivity, which is an outcome of this study, as compared to light social drinkers (Colby et al., 2004; Herrmann, Weijers, Wiesbeck, Boning, \& Fallgatter, 2001). At-risk drinkers were identified using the Alcohol Use Disorders Identification Test-Consumption, which has been used to screen for at-risk drinking among general and young adult populations (Dawson, Grant, Stinson, \& Zhou, 2005; DeMartini \& Carey, 2012; Frank et al., 2008); a score of 4 or more is considered positive for men and a score of 3 or more for women (Dawson et al., 2005). Exclusion criteria included (a) a blood alcohol content (BAC) level above $0.00 \%$ at session initiation, (b) use of a medication or current/past medical or psychiatric diseases contraindicated with stress response (e.g., hypertension), and (c) current or history of alcohol dependence or treatment for alcoholrelated problems.

Participants were recruited using diverse methods, including the undergraduate research participation pool, flyers, campus news, classroom/email solicitations, and online advertisements (e.g., Craigslist). Participants recruited from the undergraduate research participation pool (24\% of the sample) were compensated with course credit. Participants recruited from other methods $(76 \%)$ received monetary compensation of $\$ 20$. All study procedures and measures were approved by university Institutional Review Board.

\section{Study Procedures}

All videos used in the current study's experimental procedures were successfully piloted with 15 young Black adults aged 18 to 30 . Specifically, participants visited the lab to view eight video clips (mostly coming from news coverage) of actual incidents of racial discrimination that occurred in the U.S. Following the viewing of the videos, participants answered several qualitative and quantitative questions pertaining to their familiarity of the video clips, perceived level of racism exhibited, and responses to videos (i.e., affective, behavioral, physiological responses). Both Mild and Extreme racial discrimination videos 
were be reviewed for both content and length. After reviewing several video options for each condition of varying lengths, each individual was asked to rate each video on to the extent to which it exuded racism toward Blacks and was stress-provoking/upsetting. Response options ranged from 1 (not at all) to 7 (extremely). In addition, participants participated in a qualitative interview to offer a more in depth experience of the videos. Based on pilot results, clips of videos were categorized for the two conditions of Mild and Extreme based on perceived level of intensity and stressfulness exhibited. Indeed, Mild $(M=45.20 ; S D=8.52)$ and Extreme $(M=53.07 ; S D=3.37)$ video conditions demonstrated significant mean differences in regards to level of stressfulness (i.e., $t(14)=4.86, p<.001$ ). Then, video lengths were adjusted so that clips for both Mild and Extreme conditions ran for approximately five to six minutes. It is noteworthy to mention that there were differences in the eligibility criteria for participants recruited for the piloting procedures as opposed to the full experimental procedures; specifically, participants did not have to endorse at-risk levels of drinking to participate in the pilot study.

For the main study, interested participants took part in a pre-screening assessment to ensure that they were eligible for the study before scheduling an experimental session. All experimental sessions were scheduled for two hours. The eligible participants were informed that their BAC should be $0.00 \%$ at the time of the experimental session. Upon arriving to the test site, research assistants verified participant eligibility criteria, collected a baseline BAC with use of a breathalyzer (i.e., BACtrack Breathalyzers: S82), briefed participants on study procedures, and obtained written informed consent.

All study procedures are shown in Figure 2. During the baseline assessment period, participants completed a questionnaire assessing demographics, past-3-month alcohol use, racial identity, affective state, and social desirability. Participants were then connected to a heart-rate monitor by a research assistant while baseline psychophysiological responses were 
recorded; during this time, participants were asked to relax while listening to Zen music with accompanied nature-related photos. Heart-rate was measured using a chest strap Polar H7 Bluetooth heart rate monitor (Polar Electro Oy, Kempele, Finland).

Next, all study participants underwent two randomized vicarious racial discrimination video conditions. One video condition exhibited instances of Mild racial discrimination (e.g., verbal antagonizing with use of racial slurs), whereas the other video condition exhibited instances of Extreme racial discrimination (e.g., police brutality resulting in severe physical injury or mortality). Following each of the two video conditions, participants completed several tasks in the following order: a brief questionnaire including manipulation check items and a measure of negative affect, two alcohol-related outcomes (i.e., alcohol use craving and attentional bias to alcohol cues) in a randomized order, and 5 minutes of a resting period. To assess alcohol craving, participants were asked to hold a cup of alcohol provided according to their alcohol preference (among beer, wine, and liquor) and smell it for 1 minute (but not to drink the alcohol; Ramirez, Monti, \& Colwill, 2015). The same type of alcohol for a participant was given following both the Mild and Extreme conditions. After alcohol cue exposure, participants' alcohol craving was measured through the self-report Alcohol Urge Questionnaire (Bohn, Krahn, \& Staehler, 1995). For the measurement of attentional bias towards alcohol-related stimuli, participants completed an implicit visual alcohol probe task on a computer (Ehrman et al., 2002). During resting periods, participants were asked to watch and listen to Zen music with accompanied nature-related photos to allow their stress responses to decrease. At the end of the experimental procedures, participants completed a questionnaire assessing perceived experience with personal accounts of racial discrimination. Participants were then debriefed and compensated.

\section{Measures}

Demographic information. Sex $(0=$ male and $1=$ female $)$ was obtained through a 
self-report questionnaire and included as a covariate given well-documented sex differences in alcohol-related outcomes among Black drinkers (Asari \& Lankarani, 2016).

Baseline binge drinking. To assess participants' alcohol use at baseline, a computer version of the Timeline Follow Back calendars was used (Sobell \& Sobell 1992). The Timeline Follow Back calendar has demonstrated sound validity and reliability in Black young adults (e.g., Humara \& Sherman 1999; Sobell et al. 1986). Frequency of binge drinking (defined as five or more drinks on one occasion for men or four or more for women) was calculated and used as a covariate given its peak during young adulthood and its association with alcohol-related problems in comparison to other alcohol use variables (e.g., alcohol use frequency; Thompson, Stockwell, Leadbeater, \& Homel, 2014).

Perceived racial discrimination. The Schedule of Racist Events (Landrine \& Klonoff, 1996) was used to assess the frequency of racial discrimination acts directed against or toward individuals. This scale has been used to assess perceived racial discrimination experiences and its association with alcohol/substance outcomes among Black young adults (Boynton et al., 2014). The 17-item scale includes items such as "How many times have you been accused or suspected of doing something wrong (e.g., stealing, cheating, breaking the law) because you are Black?” Response options were based on a 6-point scale from 1 (never) to 6 (almost all of the time). A sum score (Cronbach's alpha $=.91)$ was calculated and used as a covariate.

Racial identity. The Multidimensional Inventory of Black Identity (Sellers, Smith, Shelton, Rowley, \& Chavous, 1998) was used to measure racial identity based on three subscales of centrality ( 8 items), private regard (6 items), and public regard (6 items). Item examples include: "Being Black is an important reflection of who I am" (centrality), "I am proud to be Black" (private regard), and "In general, other groups view Blacks in a positive manner" (public regard). Response scale ranges from 1 (Strongly Disagree) to 7 (Strongly 
Agree). Responses were reverse coded as necessary. The scale has been frequently utilized among samples of Black young adults (Mason et al., 2016). A sum score for each subscale was calculated and used as a moderator for analyses; the Cronbach's alpha was .56, .70, and .77 for the private regard, centrality, and public regard subscales, respectively. The Cronbach's alpha for private regard is notably lower than the other subscales; this is in contrast to appropriate levels of internal consistency observed in most previous studies (e.g., Bynum, Best, Barnes, \& Burton, 2008; Mason et al., 2016; Sellers et al., 1998), although some studies have demonstrated similarly lower alpha values (e.g., Ho \& Sidanius, 2010). Moreover, three outliers were identified in the private regard variable, which may have contributed to the fairly low alpha. Participants were still included in analyses because the main result of a significant interaction between private regard and vicarious racism remained the same without these three outliers.

Social desirability. Participants' tendency to produce socially desirable responses was measured using the 13-item Reynolds Short Form C of the Marlowe-Crown Social Desirability Scale (Reynolds, 1982). The scale has shown good internal reliability and has been used among samples of racially diverse young adults (Lamis \& Lester, 2012). The items include "It is sometimes hard for me to go on with my work if I am not encouraged" and "I have never deliberately said something that hurt someone's feelings". Participants responded to each item with 0 (False) or 1 (True). A sum score (Cronbach's alpha $=.69$ ) was calculated and used as a covariate.

Negative affective state. To assess negative affective state, the 10 -item negative affect subscale of the Positive and Negative Affect Schedule (Watson, Clark, \& Tellegen, 1988) was used. The scale asks participants to indicate to what extent they are experiencing a variety of feelings and emotions (e.g., distressed, hostile, ashamed) at the present moment. The response scale ranges from 1 (very slightly or not at all) to 5 (extremely). This measure 
has been validated and utilized among samples of racial minority young adults with appropriate internal reliability (Brondolo et al., 2008). A sum score (Cronbach's alpha $=.62$ ) was calculated and used as a mediator.

Alcohol use craving. Self-reported drinking craving was assessed after alcohol cue exposure using the 8-item Alcohol Urge Questionnaire (Bohn et al., 1995). This measure has been used among predominantly Black samples (Ciccolo et al., 2016). Example items include "All I want to do now is have a drink" and "It would be difficult to turn down a drink this minute". Participants responded to each item based on a 7-point response scale, with responses from 1 (Strongly Disagree) to 7 (Strongly Agree). For the current analyses, the sum scores of the eight items (Cronbach's alpha $=.91$ for Mild and .92 for Extreme conditions) after each of the two video conditions were used as dependent variables.

Alcohol attentional bias. A visual probe task is a well-established protocol to investigate participants' attentional bias towards a substance-related stimuli (Ehrman et al., 2002). Studies have suggested that people with increased urge to drink have a shorter reaction time in replacing alcohol-related images (Field \& Cox, 2008; Field \& Powell, 2007). Pairs of alcohol-related pictures (e.g., a glass of beer) and neutral pictures (e.g., a chair) were shown. A fixation point (x) was shown for 500 milliseconds (ms) in the center of the computer screen, followed by a pair of alcohol-related and neutral pictures in which one is shown in the left side and another shown in the right side for $1000 \mathrm{~ms}$. When pictures disappeared from the screen, the fixation point (x) appeared on the left or right side, and participants were asked to answer which picture was located on that side. Participants were given two blocks of 84 trials. For the current analyses, participant reaction time ratios of alcohol-related pictures to neutral pictures after each of the two video conditions were used as dependent variables.

Manipulation check. After exposure to each video condition, participants completed two items assessing racism exhibited in the videos (e.g., "To what extent do you think the 
videos evidenced racism toward Blacks?") and two items assessing stressfulness in response to videos (e.g., "To what extent did you find the videos to be stress-provoking?”). Response options ranged from 1 (not at all) to 7 (extremely). Similar questions and techniques have been utilized in studies of similar aims and designs (e.g., McCoy \& Major, 2003). A sum score of perceived racism and stressfulness was calculated separately following response to the Mild and Extreme racism conditions and used as manipulation check.

In addition, physiological (i.e., heart rate) and psychological (i.e., negative affective state) measures were used as indicators of stress reactivity. Heart rate (i.e., beats per minute) was measured throughout the duration of the experiment, however readings were averaged for baseline (i.e., average of all readings prior to video onset) and reactivity (i.e., average of readings during video display) phases. Negative affective state was measured using the 10item negative affect subscale of the Positive and Negative Affect Schedule (Watson, Clark, \& Tellegen, 1988) after each video via self-report (in addition to the aforementioned baseline survey).

\section{Data Analytic Strategy}

Descriptive analyses. All study analyses were conducted in SPSS, Version 23.

Descriptive data analyses were conducted to obtain means/percentages and bivariate correlation analyses of all study variables. In addition, manipulation check variables were assessed as a function of video conditions using paired samples $t$-tests.

Main analyses. First, two-way mixed analyses of variance (ANOVA) were conducted to examine whether the two alcohol outcomes (i.e., alcohol craving and attentional bias) differed by video condition (i.e., Extreme versus Mild vicarious racial discrimination). Four covariates were included to control for potential confounding effects: participant sex, frequency of personal accounts of racial discrimination, past 90-day binge drinking frequency, and social desirability. Second, two-way mixed analyses of variance (ANOVA) were 
conducted to examine interaction effects of racial identity (between-subject) and video condition (i.e., Mild versus Extreme; within-subject) on alcohol outcomes. In total, six sets of mixed ANOVA models were estimated separately to examine the interaction effects with each subscale of racial identity (i.e., centrality, private regard, and public regard) on the two alcohol outcomes (i.e., alcohol craving and attentional bias). Each model included (a) main effects of racial identity and video condition, (b) the racial identity-video condition mixed interaction effect, and (c) the following covariates to control for potential confounding effects: participant sex, frequency of personal accounts of racial discrimination, past 90-day binge drinking frequency, and social desirability. For significant interactions, marginal mean levels of the alcohol outcome variable were obtained in the two experimental conditions as a function of racial centrality and private regard levels (i.e., one $S D$ below the mean, the mean, and $1 S D$ above the mean).

The assumptions of ANOVA were checked before conducting any analyses. First, the assumption of no significant outliers was assessed through the use of boxplots and Z-scores. For attentional bias for alcohol scores (based on visual probe tasks) following the Extreme video condition, one participant was identified as an extreme outlier based on the boxplot (i.e., data point was more than 3 box-lengths away from the edge of the box), as well as based on Z-scores (i.e., participant had a Z-score greater than 3). This participant was subsequently dropped from analyses of attentional bias toward alcohol cues; however, this participant was retained in analyses of alcohol craving. Then, the assumption of normality was assessed using visual inspection of histograms and skewness and kurtosis measures; given the normal range of skewness (values ranged from 0.05 to 1.01) and kurtosis (values ranged from - 0.03 to 1.10), data transformations were not implemented (Trochim \& Donnelly, 2006; Gravetter \& Wallnau, 2014). Other assumptions were automatically met based on the current study 
design (i.e., the dependent variables were continuous, the same group of participants were exposed to both Mild and Extreme conditions).

Ancillary analyses of mediating effects of negative affect state. For any significant interaction effect between racial identity and vicarious racism, mediated moderation analyses were conducted to examine whether negative affect reactivity explains how the interaction contributes to alcohol outcomes. The SPSS macro PROCESS was used to test for significant mediated moderation (Hayes, 2013). Estimates of mediated effects and their 95\% confidence intervals were obtained by bootstrap analysis with 5,000 bootstrap samples. A $95 \%$ confidence interval (CI) of the mediated effect that does not include zero indicates a significant mediation effect.

Power analysis. A priori power analyses were conducted using G*Power to determine the required sample size to detect interaction effects of racial identity and experimental conditions on a continuous outcome variable of alcohol use craving and attentional bias to alcohol cues. Given the absence of empirical studies on vicarious racial discrimination and alcohol outcomes, an experimental study of the interaction effect between personal experiences of racial discrimination and racial identity on willingness to use alcohol by Stock and colleagues (2011) was used to obtain an effect size for power analyses.

Although an effect size was not provided, $\mathrm{f}^{2}$ value of.30 (corresponding to a medium-to-large effect size; Cohen, 1988) was calculated by descriptive statistics (i.e., standardized coefficient and standard deviation of the outcome variable; Lenhard \& Lenhard, 2016). Fifty participants were needed to achieve a power of .80 and a two-tailed $\alpha$ level of .05 , and thus, the sample size of 51 provided sufficient power to detect an interaction effect of vicarious racism and racial identity (if existed). We did not have sufficient power to detect the mediating effect of negative affect unless large effect sizes were assumed (Fritz \& 
MacKinnon, 2007), and thus the mediation test was conducted as exploratory ancillary analyses to inform future studies with bigger sample sizes.

\section{Results}

\section{Descriptive Statistics}

Participants were on average 21 years old $(S D=3.02$, range $=18-29), 82 \%$ college students, and $60 \%$ female. On average, participants engaged in binge drinking on seven of the past 90 days $(S D=7.25)$, similar to levels observed among other samples of Black young adults (O'hara, Armeli, Scott, Covault, \& Tennen, 2015). Most participants preferred wine as opposed to beer and distilled spirits (45\%); this is incongruent with previous findings (Kerr, Patterson, \& Greenfield, 2009). Bivariate correlation coefficients of study variables are presented in Table 1. Alcohol use craving after Mild and Extreme videos conditions were positively correlated with each other, $r=.83, p<.001$, but alcohol attention bias measured after Mild and Extreme video conditions were not $(r=.06, p=.55)$. Positive associations of baseline racial discrimination with several experimental condition variables were found, including alcohol use craving score following the Extreme video condition $(r=.33, p=.02)$ and negative affect following both video conditions $(r$ 's $=.31-.43, p$ 's $=.00-.03)$. Racial centrality and private regard, but not public regard $(r=.15, p=.28)$, demonstrated positive associations with perceived racism following Mild video conditions ( $r$ 's $=.32-.48, p$ 's $=.00$ $-.02)$.

\section{Manipulation Check}

Changes of perceived racism ratings, perceived stress, negative affect, and heart-rate responses in Mild and Extreme video conditions are presented in Table 2. The mean differences as a function of the vicarious racial discrimination video conditions (i.e., Mild and Extreme) on the aforementioned measures was examined using paired samples $t$-tests. Overall results showed that the experimental conditions were successfully manipulated as 
indicated by significant condition differences. Regarding perceived negative affect, a significant mean difference as function of video condition was found, $t(50)=-5.81, p<.001$. Specifically, participants reported greater levels of negative affect following the Extreme ( $M$ $=31.41 ; S D=8.27)$ as opposed to Mild $(M=26.33 ; S D=7.88)$ condition. The same pattern was found for perceived stressfulness, $t(50)=-3.40, p=.001$, and heart rate, $t(50)=-2.74, p$ $=.01$. The level of stressfulness measured right after the Extreme condition $(M=13.55 ; S D=$ 1.03) was significantly higher than right after the Mild condition $(M=12.71 ; S D=1.79)$. Also, heart rate (i.e., mean values of five minutes each measured in both conditions) was significantly higher in the Extreme condition $(M=90.05 ; S D=24.23)$ in comparison to the Mild condition $(M=85.55 ; S D=20.36)$.

\section{Main Analyses of Alcohol-Related Outcomes}

Effects of video conditions (without consideration of racial identity). Results of mixed ANOVA showed no significant differences as a function of the two video conditions both in alcohol craving, $F(1,44)=0.37, p=.54, n_{p}{ }^{2}=.01$ and in alcohol attentional bias, $F(1,42)=0.26, p=.61, n_{p}{ }^{2}=.01$, after controlling for the covariates of baseline racial discrimination, binge drinking, sex, and social desirability. Further, the effect of video conditions on the two alcohol outcomes did not differ across any of the covariates, $p$ 's $=.40$ to .99 .

Interaction effects between racial identity and video conditions. Results of mixed ANOVA to test experimental condition and racial identity interaction effects on alcohol outcomes are presented in Table 3. For the alcohol use craving outcome, analyses demonstrated significant interaction effects of racial centrality with experimental condition in predicting self-reported alcohol use craving, $F(1,43)=7.37, p=.01, n_{p}{ }^{2}=.15$, after controlling for baseline racial discrimination, binge drinking, sex, and social desirability. Similar patterns of results were observed for private regard. Specifically, there was a 
statistically significant interaction between the experimental conditions and private regard on alcohol use craving, $F(1,43)=6.99, p=.01, n_{p}{ }^{2}=.14$. Significant interaction or main effects were not found in the models pertaining to public regard. For the alcohol attentional bias outcome, mixed ANOVA demonstrated a non-significant main and interaction effects for all three racial identity models.

To illustrate the pattern of significant interactions between racial identity and vicarious racial discrimination on alcohol use craving, Figure 3 shows estimated marginal means of alcohol use craving in Mild and Extreme vicarious racial discrimination experimental conditions as a function of racial identity levels. Figure 3 demonstrates that participants with high racial centrality (one $S D$ above the mean) reported greater alcohol use craving than those with low racial centrality (one $S D$ below the mean) after the Extreme vicarious racism condition, whereas there was no difference in alcohol craving as a function of centrality after the Mild vicarious racism condition. In contrast, participants high in racial private regard reported lower alcohol use cravings than those with low private regard after the Mild vicarious racial discrimination condition, whereas there was no difference in alcohol craving as a function of private regard after the Extreme vicarious racism condition.

\section{Ancillary Analysis of Mediating Effects of Negative Affect.}

Mediation analyses were conducted to test mediating roles of negative affect state in the significant interaction effect of racial centrality and experimental condition on alcohol use craving, as well as the significant interaction effect of private regard and experimental condition on alcohol use craving. No significant mediation effects of negative affect state were indicated in the model with racial centrality, $b=-0.03,95 \%$ bootstrapped CI $[-0.21$, $0.11], S E=0.08, \beta=-.03$. Specifically, the indirect path from racial centrality to negative affect state change between Mild and Extreme conditions $(b=-0.12, S E=0.13, p=.34)$, as well as the indirect path from negative affect state to alcohol use craving change between 
Mild and Extreme conditions ( $b=0.21, S E=0.20, p=.30$ ) were not significant, after controlling for covariates (i.e., sex, personal accounts of racial discrimination, social desirability, and binge drinking). In addition, no significant mediation effects of negative affect state were indicated in the model with private regard, $b=-0.03,95 \%$ bootstrapped CI $[-0.09,0.11], S E=0.05, \beta=-.01$. Specifically, the indirect path from private regard to negative affect state change between Mild and Extreme conditions $(b=-0.17, S E=0.25, p$ $=.51$ ), as well as the indirect path from negative affect state to alcohol use craving change between Mild and Extreme conditions $(b=0.18, S E=0.20, p=.36)$ were not significant, after controlling for covariates.

\section{Discussion}

This is to my understanding the first demonstration of the associations between vicarious racism and alcohol outcomes among Black young adult drinkers. This novel investigation also extended previous observational studies of racial discrimination by examining the effect of experimentally manipulated discrimination. Moreover, the current study explored the role of racial identity (i.e., centrality, private regard, and public regard) as potential moderators in the association of vicarious racial discrimination and alcohol-related outcomes. Findings showed that, after accounting for sex, social desirability, and baseline frequencies of binge drinking and racial discrimination, racial centrality was positively associated with alcohol use craving, particularly in the extreme vicarious racial discrimination condition. In contrast, private racial regard was negatively associated with alcohol use craving, particularly in the mild vicarious racial discrimination condition. No significant findings were observed for the alcohol attentional bias outcome. No significant interactions were observed for public regard. Overall, these findings suggest that, while private regard of one's Black racial identity may buffer the impact of vicarious exposure to 
racial discrimination, centrality of one's Black racial identity may exacerbate its effects on alcohol-related outcomes.

\section{Main Effects of Vicarious Racism Conditions}

In contrast to what was expected, there were no differences in alcohol use craving and attentional bias to alcohol use as a function of the two video conditions. Such findings might suggest that when not exploring specific individual difference factors, vicarious racial discrimination may be related to alcohol-related behaviors, irrespective of the level and intensity of vicarious racism. Thus, there is no overall effect of vicarious racial discrimination on alcohol outcomes may exist among young Black adults. However, future research may seek to explore the role of vicarious racism on other adverse outcomes to which a health disparity exists among the Black population.

\section{Differing Effects of Racial Identity Components}

Findings indicate that racial centrality exacerbates reactivity (in terms of alcohol craving) to vicarious experiences of racial discrimination. Racial centrality (i.e., significance of being Black) may predispose Black individuals to be sensitive to and vigilant about incidents of racism, even those that are not their own, leading to negative reactions followed by adverse coping behaviors (Mason et al., 2016). It is possible that those high in their own racial centrality strongly identified with the victims portrayed in the video conditions, thereby causing the stressor to be significantly more damaging. Indeed, threats to one's racial group may be experienced as threats to the self (McCoy \& Major, 2003; Yip et al., 2008).

Furthermore, high centrality does not necessarily denote that one feels positively about their race. High centrality people might often live in a state of worry because their high racial identity makes them aware of the detriment of being Black (Hoggard, Byrd, \& Sellers, 2015). Although the current finding is consistent with previous research (e.g., Burrow \& Ong; McCoy \& Major, 2003; Yip et al., 2008), it diverts from previous null findings (e.g. Caldwell 
et al., 2004; Fuller-Rowell et al., 2012; Richman et al., 2013), possibly due to differences in types of discrimination examined and/or low statistical power of previous studies. Continued research is warranted to replicate the role of centrality in the vicarious versus personal discrimination-alcohol relationship.

In contrast to centrality and consistent with hypotheses, it appears that racial private regard (personal evaluative judgment of being Black) is protective against the deleterious effects of vicarious racial discrimination. This finding is consistent with previous research findings on alcohol use (e.g., Caldwell et al., 2004; Richman et al., 2013) and suggests that feeling positively about one's racial group may be particularly beneficial for Black young adults subsequently endorsing lower levels of alcohol use craving. Personal positive attitudes about being Black likely help young adults reject the harmful messages implicit in racism and deflect the message's emotional impact (Collins, 2000). Indeed, the high degree of collectivism found in Black culture (Jones, 2003; Oyserman, Gant, \& Ager, 1995) is said to allow Black individuals to focus on the unique strengths of their group in determining their sense of worth and well-being. Moreover, those who feel negatively about their status as a Black person (i.e., low private regard) may not be able to de-identify with society's perspective on being Black (e.g., Blacks are inferior). This may ignite adverse emotional and cognitive responses, to which individuals attempt to alleviate with alcohol use.

Counter to predictions, public regard was not found to significantly buffer or exacerbate the vicarious discrimination-alcohol association. Limited research (e.g., Sellers \& Shelton, 2003; Sellers, Copeland-Linder, Martin, \& Lewis, 2006) has shown that those individuals who believe that others hold negative views of Blacks (i.e., low public regard) are less negatively impacted by racial stressors. However, such studies have examined the effect of personal experiences of racism on broader mental health outcomes (e.g., psychological distress), as opposed to the effect of vicarious experiences of racism on risky health behaviors 
such as substance use indicators. Thus, current null findings suggest that public regard may not influence vulnerability to high-risk health outcomes in response to vicarious racial discrimination. Moreover, public regard perceptions may reflect an individual's encapsulated belief about others' evaluations of Black people, but not necessarily impact their personal behavior, in this case their alcohol-related behaviors. Overall, fewer studies have examined the impact of public regard in the association of racial discrimination with health outcomes in comparison to the number of studies on centrality and private regard. Additional research is needed to elucidate the necessary conditions under which public regard shapes how Blacks respond to vicarious versus personal racial discrimination.

\section{Ancillary Findings regarding Underlying Negative Affective Mechanisms}

Ancillary analyses indicated that negative affect was not found to serve as an underlying mechanism of any of the moderated associations. This is in contrast to previous theoretical frameworks (e.g., Harrell, 2002) and empirical evidence (e.g., Desalu et al., 2017) regarding the underlying negative affective mechanisms in the association of racial discrimination with alcohol outcomes. However, several explanations may help explain the null findings. First, null findings could be due to low statistical power as a result of the study's sample size. Alternatively, previous research has solely focused on mediation models of perceived personal racial discrimination (Boynton et al., 2014; Desalu et al., 2017). The distinct differences in types of racial discrimination assessed, alongside the cross-sectional nature of prior works, may explain the differing results. Finally, the current study examined a broad measure of negative affect, which inhibits exploration of specific affective responses. Recent research suggests that specific affective response may be better explored as links to the discrimination and alcohol and substance use association; although scarce, there is research highlighting externalizing reactions (i.e., anger and hostility) as the operative affective response (Gibbons et al., 2010). If there is a causal relation between vicarious racial 
discrimination and alcohol use, it will be important for future research to determine what specific types of affect or distress mediates that relation.

\section{Clinical Implications}

The current study has potential clinical implications for prevention/intervention efforts to curtail racism-induced drinking. Preventative efforts may aid Black young adults in developing an understanding of psychological responses to discrimination footage to know when it may be time to close one's phone screen or turn off the television (Adetiba \& Almendrala, 2016); this may ultimately lessen their repeated exposure to vicarious racism. In addition, both prevention and intervention efforts may seek to help Black young adults strengthen their racial identity, particularly their ability to identify positive aspects of being Black (i.e., private regard) despite the negative race-related messages they may be exposed to. Furthermore, the current findings highlight the need for process-oriented groups for young Black adults to provide them with a safe place to share, explore, and heal from their racial experiences (Bogart et al., 2013; Carter \& Forsyth, 2010; Elligan \& Utsey, 1999). Processoriented groups designed to aid with the effects of racism among Blacks has been shown to result in reduction of negative affect, including anger and frustration, as well as increases one's sense of camaraderie (Elligan \& Utsey, 1999; Brondolo, Brady, Pencille, Beatty, \& Contrada, 2009). Psychologists, as well as social advocacy groups (e.g., Black Lives Matter) and college campuses, can aid in both the development and execution of process support groups. Moreover, mental health professionals should remain open to discussing racial trauma and conceptualizing racial trauma as a part of clients' presenting problems. Racial trauma (also known as race-based traumatic stress) refers to the stressful impact or emotional pain of one's experience with racism and discrimination (Carter, 2007). Finally, involvement in prosocial activities (e.g., donating time or money to community service efforts geared toward Black populations, volunteering for campaigns) may help young Black individuals 
feel a part of fight to end racism, as opposed to solely a victim. Indeed, it has been shown that some young Black adults feel a sense of agency and motivation to improve conditions for Black individuals after viewing them unjustly disregarded by society (White-Johnson, 2012).

\section{Limitations}

There are some noteworthy limitations of the current study. First, the study findings do not display whether exposure to vicarious racial discrimination is related to actual alcohol use. Nonetheless, alcohol use craving and alcohol attentional bias are important constructs in addiction research (Skinner et al., 2010) and these widely used cognitive-based measures often function as a proxy for alcohol use (Sinha \& O'Malley, 1999; Wapp, Burren, Znoj, \& Moggi, 2015). In addition, the current study only represents the momentary effects of vicarious racial discrimination. Exposure to racial discrimination and its negative psychological effects are both chronic and accumulative (Geronimus, Hicken, Keene, \& Bound, 2006; Williams \& Mohammed, 2009), which cannot be captured in a laboratory study. In addition, Black young adults were recruited for the purposes of this study given that this is a critical period for peak alcohol use and consequences; however, results may not be generalizable to other age groups including Black adolescents or older adults. Finally, the modest sample size precluded drawing conclusions regarding the mediating role of negative affect status and conducting further sub-group analyses as a function of binge drinking or sex due to limited statistical power. Of note, the limited sample size may be in part due to Black individuals reluctance in participating in scientific research, as opposed to inadequate recruitment efforts. Another important consideration is the manipulation of the Mild and Extreme video conditions. Although manipulation of the conditions were deemed successful, the observed differences could be due to additional factors above and beyond racial discrimination. For example, participants could have responded more strongly to the Extreme video conditions because it exhibited physically aggressive behaviors, whereas minimal to no 
physical aggression was displayed in the Mild condition. Future research efforts focused on the topic of vicarious discrimination may utilize control conditions that can better disentangle the differing effects.

\section{Future Directions}

Notwithstanding the study's limitations, the current findings may help inform future research. It is important to recognize that racial identity attitudes do not operate in isolation of one another. Given their intercorrelation in the current study, private regard may be especially protective when it is coupled with other high levels of racial identity (e.g., centrality). Moreover, although racial identity has been traditionally explored as a moderator, it may be worthwhile to explore its role as a possible mediator. In addition, specific affective responses have been highlighted as common following exposure to racial discrimination (e.g., anger, anxiety; Gibbons et al., 2010). Future research may seek to explore the role of specific affective underlying mechanisms, as opposed to negative affect broadly as was done in the current study. The current study specifically sought to recruit Black young adults, however, it is unclear how age may modify the vicarious racial discrimination-health outcome relationship and warrants further investigation. As opposed to including age as a covariate, studies may seek to understand how findings may differ as a function of this sociodemographic factors. Indeed, a previous meta-analytic review (e.g., Desalu et al., 2019) indicated that the association of racial discrimination and certain drinking outcomes are stronger among studies of younger samples of Black individuals. Lastly, the current study recruited participants from a university and city that was limited in Black representation. Findings should be replicated with samples from settings with greater Black representation such as historically Black colleges/universities. Finally, future research can directly address the current study's limitations by replicating the study with larger sample sizes and implementing an alcohol administration design. 


\section{Conclusion}

Although research on racism as has proliferated over the past few decades, there is still much more to discover about how racial discrimination and racial identity are related to adverse alcohol-related outcomes that young Black adults are disproportionately affected by. A better understanding of racially-relevant risk and protective factors and within-group differences of Black persons will ultimately lead to more effective individual- and community-level interventions that can serve to reduce health disparities in Black communities. 
Table 1

Correlation Coefficients of Study Variables $r$

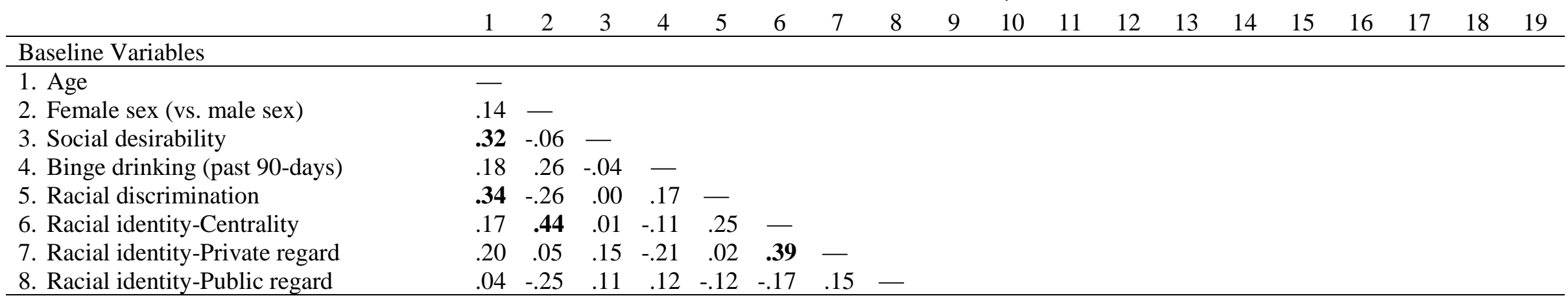

Experimental Variables for Mild and Extreme Video Conditions

Experimental V ariables for Mild and Extreme Video Conditions

9. Heart-rate (Mild)

$\begin{array}{rrrrrrrrrr}-.14 & .39 & .01 & -.11 & -.10 & .05 & .03 & -.14 & - & \\ -.05 & .44 & .11 & .01 & -.08 & .09 & -.02 & -.14 & \mathbf{. 8 8} & -\end{array}$

10. Heart-rate (Extreme)

$\begin{array}{rrrrrrrrrr}.05 & .44 & .11 & .01 & -.08 & .09 & -.02 & -.14 & \mathbf{. 8 8} & - \\ .17 & -.04 & -.05 & -.01 & .24 & .02 & -.19 & -.03 & -.23 & -.17\end{array}$

11. Alcohol craving (Mild)

12. Alcohol craving (Extreme)

$\begin{array}{llllllllllll}.26 & -.09 & -.03 & .07 & .33 & .21 & .01 & .06 & -.25 & -.22 & .83 & -\end{array}$

13. Alcohol attention bias (Mild)

14. Alcohol attention bias (Extreme)

$\begin{array}{lllllllllllll}.26 & -.32 & .03 & -.08 & .09 & -.06 & .21 & .10 & \mathbf{- . 4 0} & \mathbf{- . 4 6} & .09 & .16 & -\end{array}$

15. Negative affect (Mild)

16. Negative affect (Extreme)

17. Racism rating (Mild)

18. Racism rating (Extreme)

19. Stressfulness rating (Mild)

20. Stressfulness rating (Extreme)

$\begin{array}{llllllllllllll}-.08 & -.15 & .07 & -.02 & .01 & .19 & .21 & -.11 & .04 & -.03 & -.06 & .08 & .06 & -\end{array}$

$\begin{array}{lllllllllllllll}.09 & .08 & .04 & .11 & .43 & .04 & .07 & .05 & .01 & -.00 & .16 & .09 & -.18 & -.13 & -\end{array}$

$\begin{array}{lllllllllllllllll}.20 & .04 & -.05 & .18 & .31 & .08 & .07 & -.17 & .19 & .13 & .20 & .20 & -.18 & .01 & \mathbf{. 7 0} & -\end{array}$

$\begin{array}{llllllllllllllllll}.11 & .27 & .11 & -.06 & .12 & . \mathbf{4 8} & .32 & .15 & -.08 & .07 & -.11 & -.05 & -.01 & .01 & .17 & .09 & -\end{array}$

$\begin{array}{llllllllllllllllll}-.02 & -.02 & -.15 & .02 & .08 & .18 & .20 & -.18 & .11 & .11 & .10 & .16 & -.06 & .38 & -.07 & .19 & .13 & -\end{array}$

$\begin{array}{lllllllllllllllllll}.06 & .16 & .27 & -.13 & .18 & \mathbf{. 5 0} & .44 & -.07 & -.02 & -.04 & -.01 & -.01 & -.06 & .06 & \mathbf{3 7} & .11 & \mathbf{. 3 5} & -.09 & -\end{array}$

Note. $N=48-51$ due to missing data and removed outliers. Significant group differences at $p<.05$ are highlighted in bold font. 
Table 2

Mean Comparisons of Study Variables as a Function of Video Condition

\begin{tabular}{lccc}
\hline & Mild Condition & Extreme Condition & Comparison \\
\hline Racism Rating & 13.51 & 13.57 & $t(50)=-0.26$ \\
Stressfulness & $\mathbf{1 2 . 7 1}$ & $\mathbf{1 3 . 5 5}$ & $\boldsymbol{t}(\mathbf{5 0})=\mathbf{- 3 . 4 0} * *$ \\
Negative Affect & $\mathbf{2 6 . 3 3}$ & $\mathbf{3 1 . 4 1}$ & $\boldsymbol{t}(\mathbf{5 0})=\mathbf{- 5 . 8 1} * * *$ \\
Heart Rate & $\mathbf{8 5 . 5 5}$ & $\mathbf{9 1 . 0 5}$ & $\boldsymbol{t}(\mathbf{5 0})=\mathbf{- 2 . 7 4 * *}$ \\
\hline
\end{tabular}

Note. $N=48-51$ due to missing data and removed outliers. Paired samples $t$-tests were used for comparisons; Significant comparisons between the two conditions at $p<.05$ are highlighted in bold font.

$* p<.05 . * * p<.01 . * * * p<.001$. 
Table 3

Mixed ANOVA Analyses Examining Interaction Effects of Racial Identity and Experimental Condition

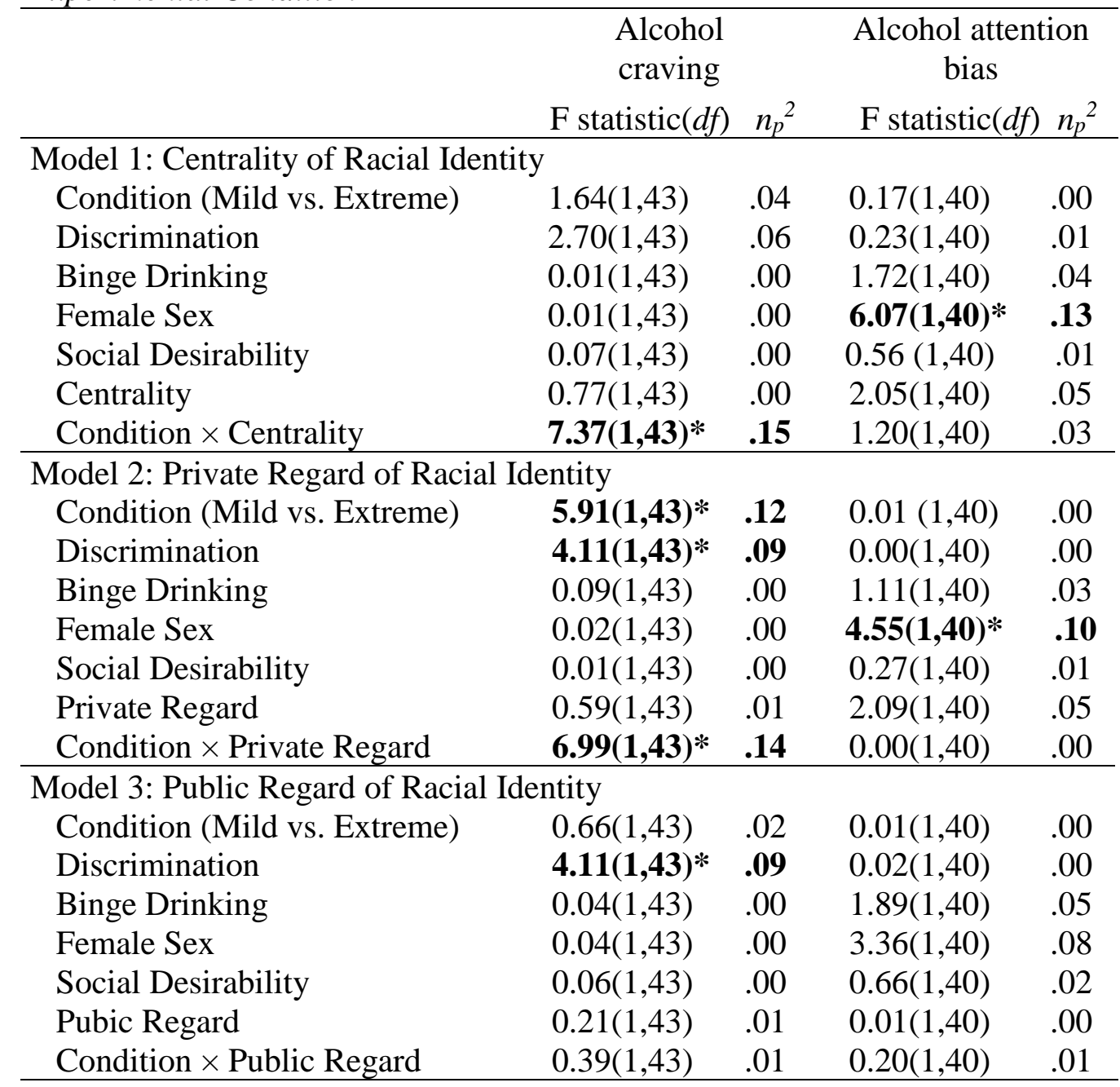

Note. $N=48-51$ due to missing data and removed outliers. Significant statistics of at least $p<.05$ are highlighted in bold.

$* p<.05 . * * p<.01 . * * * p<.001$. 


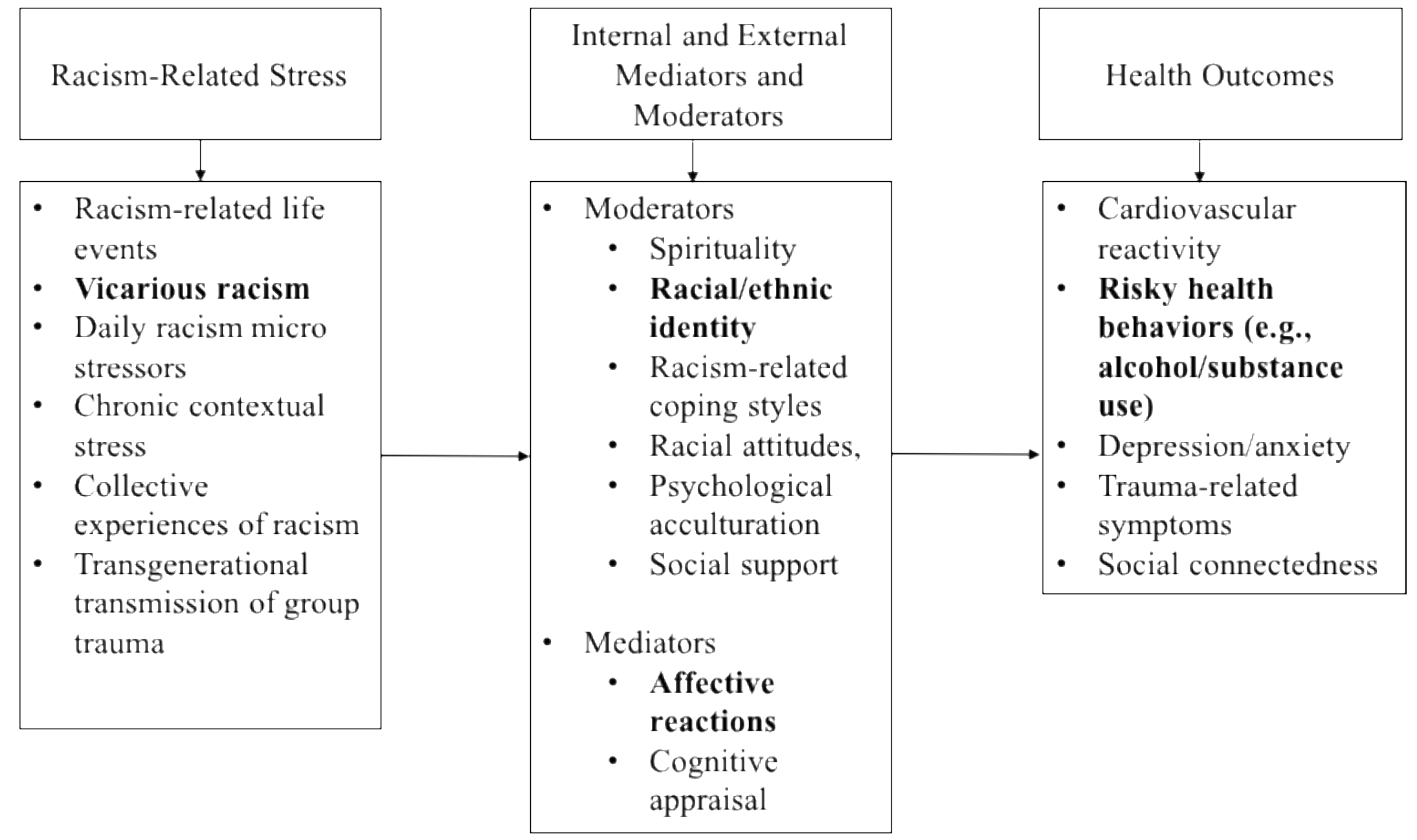

Figure 1. Theoretical framework of the Multidimensional Conceptualization for Racism-Related Stress (Harrell, 2002). 


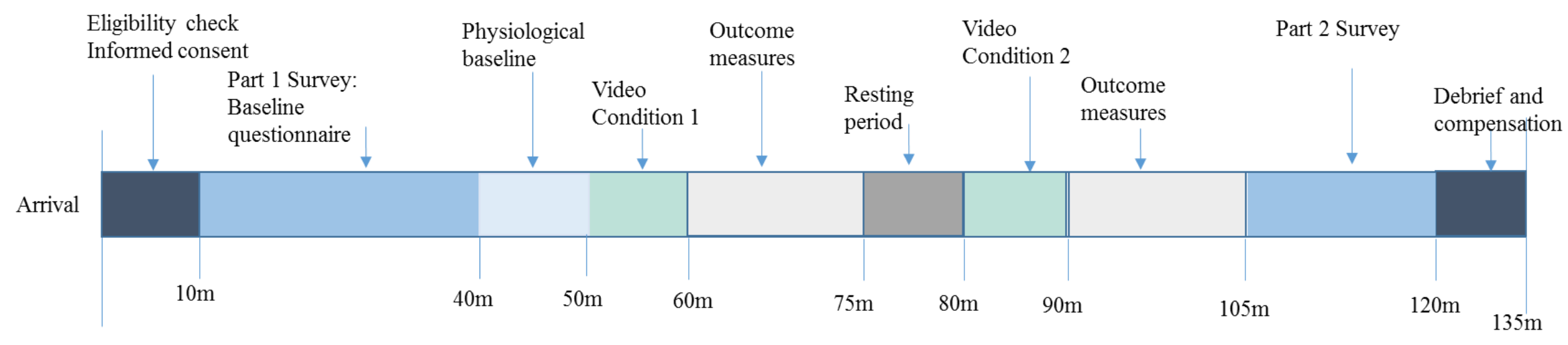

Figure 2. Experimental protocol; $\mathrm{m}=$ minutes. Order of video conditions (i.e., Mild and Extreme) and alcohol outcome measures were randomized for each participant. 


\section{Racial Centrality}

30

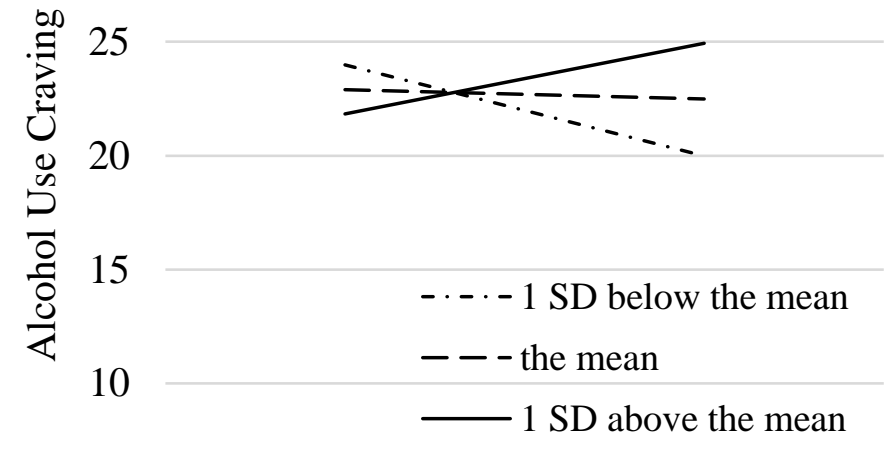

5

0

Mild Vicarious

Racism

\section{Extreme Vicarious \\ Racism}

Private Regard

30

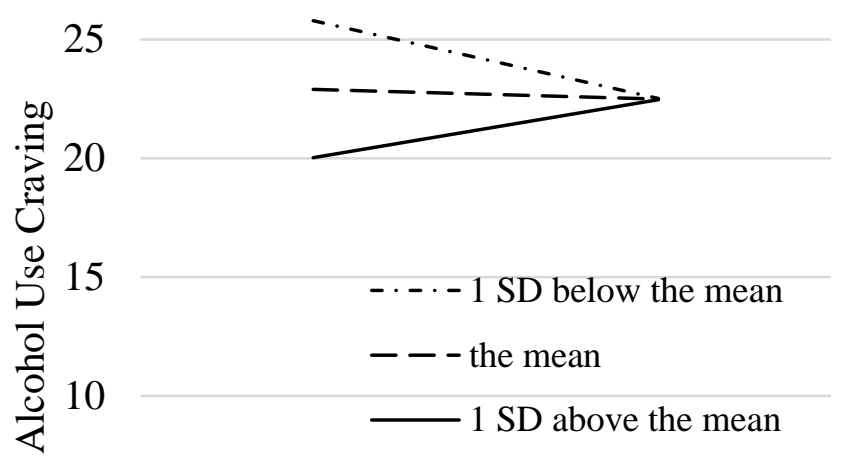

5

0

Mild Vicarious Extreme Vicarious

Racism

Racism

Figure 3. Estimated marginal means of alcohol use craving in mild and extreme vicarious racial discrimination experimental conditions as a function of racial centrality and private regard levels (i.e., one SD below the mean, the mean, and one SD above the mean). 


\section{References}

Adetiba, L. \& Almendrala, A. (2016, September 20). Watching videos of police brutality can traumatize you, especially if you're Black. Black Voices. Retrieved from http://www.huffingtonpost.com/entry/watching-police-brutalityvideos_us_577ee9b3e4b0344d514eaa5d

Alvarez, L., \& Blinder, A. (2015, June 18). Recalling nine spiritual mentors, gunned down during night of devotion. The New York Times. Retrieved from http://www.nytimes.com/2015/06/19/us/nine-victims-of- charleston-church-shootingremembered.html?_r 0

Bogart, L. M., Elliott, M. N., Kanouse, D. E., Klein, D. J., Davies, S. L., Cuccaro, P. M., ... \& Schuster, M. A. (2013). Association between perceived discrimination and racial/ethnic disparities in problem behaviors among preadolescent youths. American Journal of Public Health, 103, 1074-1081.

Bohn, M. J., Krahn, D. D., \& Staehler, B. A. (1995). Development and initial validation of a measure of drinking urges in abstinent alcoholics. Alcoholism: Clinical and Experimental Research, 19, 600-606.

Borrell, L. N., Jacobs, D. R., Williams, D. R., Pletcher, M. J., Houston, T. K., \& Kiefe, C. I. (2007). Self-reported racial discrimination and substance use in the Coronary Artery Risk Development in Adults Study. American Journal of Epidemiology, 166, 10681079.

Borrell, L. N., Kiefe, C. I., Diez-Roux, A. V., Williams, D. R., \& Gordon-Larsen, P. (2013). Racial discrimination, racial/ethnic segregation, and health behaviors in the CARDIA study. Ethnicity \& Health, 18, 227-243.

Borrell, L. N., Roux, A. V. D., Jacobs Jr, D. R., Shea, S., Jackson, S. A., Shrager, S., \& Blumenthal, R. S. (2010). Perceived racial/ethnic discrimination, smoking and alcohol 
consumption in the Multi-Ethnic Study of Atherosclerosis (MESA). Preventive Medicine, 51, 307-312.

Boynton, M. H., O’Hara, R. E., Covault, J., Scott, D., \& Tennen, H. (2014). A mediational model of racial discrimination and alcohol-related problems among African American college students. Journal of Studies on Alcohol and Drugs, 75, 228-234.

Brondolo, E., Brady, N., Thompson, S., Tobin, J. N., Cassells, A., Sweeney, M., ... \& Contrada, R. J. (2008). Perceived racism and negative affect: Analyses of trait and state measures of affect in a community sample. Journal of Social and Clinical Psychology, 27, 150-173.

Brondolo, E., Brady, N, Pencille, M., Beatty, D., \& Contrada, R. J. (2009). Coping with racism: A selective review of the literature and a theoretical and methodological critique. Journal of Behavioral Medicine, 32, 64-88.

Burrow, A. L., \& Ong, A. D. (2010). Racial identity as a moderator of daily exposure and reactivity to racial discrimination. Self and Identity, 9, 383-402.

Bynum, M. S., Best, C., Barnes, S. L., \& Burton, E. T. (2008). Private regard, identity protection and perceived racism among African American males. Journal of African American Studies, 12, 142-155.

Caldwell, C. H., Antonakos, C. L., Tsuchiya, K., Assari, S., \& De Loney, E. H. (2013). Masculinity as a moderator of discrimination and parenting on depressive symptoms and drinking behaviors among nonresident African-American fathers. Psychology of Men \& Masculinity, 14, 47-58.

Caldwell, C. H., Sellers, R. M., Bernat, D. H., \& Zimmerman, M. A. (2004). Racial identity, parental support, and alcohol use in a sample of academically at-risk African American high school students. American Journal of Community Psychology, 34, 7182. 
Carter, R. T. (2007). Racism and psychological and emotional injury: Recognizing and assessing race-based traumatic stress. The Counseling Psychologist, 35, 13-105.

Carter, R. T., \& Forsyth, J. (2010). Reactions to racial discrimination: Emotional stress and help-seeking behaviors. Psychological Trauma: Theory, Research, Practice, and Policy, 2, 183-191.

Center for Behavioral Health Statistics and Quality. (2016). 2015 National Survey on Drug Use and Health: Detailed Tables. Substance Abuse and Mental Health Services Administration, Rockville, MD.

Chaplin, T. M., Hong, K., Bergquist, K., \& Sinha, R. (2008). Gender differences in response to emotional stress: an assessment across subjective, behavioral, and physiological domains and relations to alcohol craving. Alcoholism: Clinical and Experimental Research, 32, 1242-1250.

Ciccolo, J. T., Whitworth, J. W., Dunsiger, S. I., SantaBarbara, N. J., Nosrat, S., \& LaBrec, J. E. (2016). Acute effects of resistance exercise on affect, arousal, and urge to drink in temporarily abstinent young adult hazardous drinkers: Resistance exercise and alcohol. The American Journal on Addictions, 25, 623-627.

Clark, R., Anderson, N. B., Clark, V. R., \& Williams, D. R. (1999). Racism as a stressor for African Americans: A biopsychosocial model. American Psychologist, 54, 805-816.

Clarke, N., Kim, S. Y., White, H. R., Jiao, Y., \& Mun, E. Y. (2013). Associations between alcohol use and alcohol-related negative consequences among Black and White college men and women. Journal of Studies on Alcohol and Drugs, 74, 521-531.

Cohen J. E. (1988). Statistical power analysis for the behavioral sciences. Hillsdale, NJ: Lawrence Erlbaum Associates

Collins, P. H. (2000). Black feminist thought: Knowledge, consciousness, and the politics of empowerment. New York: Routledge 
Cooper, H. L., \& Fullilove, M. (2016). Excessive police violence as a public health issue. Journal of Urban Health, 93, 1-7.

Cooper, M. L., Krull, J. L., Agocha, V. B., Flanagan, M. E., Orcutt, H. K., Grabe, S., ... \& Jackson, M. (2008). Motivational pathways to alcohol use and abuse among Black and White adolescents. Journal of Abnormal Psychology, 117, 485-501.

Davis, C. G., Thake, J., \& Vilhena, N. (2010). Social desirability biases in self-reported alcohol consumption and harms. Addictive Behaviors, 35, 302-311.

Dawson, D. A., Grant, B. F., Stinson, F. S., \& Zhou, Y. (2005). Effectiveness of the derived alcohol use disorders identification test (AUDIT-C) in screening for alcohol use disorders and risk drinking in the US general population. Alcoholism: Clinical and Experimental Research, 29, 844-854.

DeMartini, K. S., \& Carey, K. B. (2012). Optimizing the use of the AUDIT for alcohol screening in college students. Psychological Assessment, 24, 954-963.

Desalu, J. M., Goodhines, P. A., \& Park, A. (2019; Epub ahead of print). Racial discrimination and alcohol use and alcohol-related consequences among Black individuals: A meta-analytic review. Addiction. DOI: 10.1111/add.145781

Desalu, J. M., Kim, J., Zaso, M. J., Corriders, S. R., Loury, J. A., Minter, M. L., \& Park, A. (2017; Epub ahead of print). Racial discrimination, binge drinking, and negative drinking consequences among black college students: Serial mediation by depressive symptoms and coping motives. Ethnicity \& Health. 2017 Sep 21:1-15. DOI:

$10.1080 / 13557858.2017 .1380170$

Drummond, D. C. (2000). What does cue-reactivity have to offer clinical research?. Addiction, 95, 129-144.

Ehrman, R. N., Robbins, S. J., Bromwell, M. A., Lankford, M. E., Monterosso, J. R., \& O'Brien, C. P. (2002). Comparing attentional bias to smoking cues in current smokers, 
former smokers, and non-smokers using a dot-probe task. Drug and Alcohol Dependence, 67, 185-191.

Elligan, D., \& Utsey, S. (1999). Utility of an African-centered support group for African American men confronting societal racism and oppression. Cultural Diversity and Ethnic Minority Psychology, 5, 156-165.

English, D., Lambert, S. F., Evans, M. K., \& Zonderman, A. B. (2014). Neighborhood racial composition, racial discrimination, and depressive symptoms in African Americans. American Journal of Community Psychology, 54, 219-228.

Fang, C. Y., \& Myers, H. F. (2001). The effects of racial stressors and hostility on cardiovascular reactivity in African American and Caucasian men. Health Psychology, 20, 64-70.

Feagin, J. R., \& Sikes, M. P. (1994). Living with racism: The black middle-class experience. Beacon Press.

Field, M., \& Cox, W. M. (2008). Attentional bias in addictive behaviors: a review of its development, causes, and consequences. Drug and Alcohol Dependence, 97, 1-20.

Field, M., Mogg, K., Zetteler, J., \& Bradley, B. P. (2004). Attentional biases for alcohol cues in heavy and light social drinkers: the roles of initial orienting and maintained attention. Psychopharmacology, 176, 88-93.

Field, M., \& Powell, H. (2007). Stress increases attentional bias for alcohol cues in social drinkers who drink to cope. Alcohol \& Alcoholism, 42, 560-566.

Frank, D., DeBenedetti, A. F., Volk, R. J., Williams, E. C., Kivlahan, D. R., \& Bradley, K. A. (2008). Effectiveness of the AUDIT-C as a screening test for alcohol misuse in three race/ethnic groups. Journal of General Internal Medicine, 23, 781-787.

Fritz, M. S., \& MacKinnon, D. P. (2007). Required sample size to detect the mediated effect. Psychological Science, 18, 233-239. 
Fuller-Rowell, T. E., Cogburn, C. D., Brodish, A. B., Peck, S. C., Malanchuk, O., \& Eccles, J. S. (2012). Racial discrimination and substance use: Longitudinal associations and identity moderators. Journal of Behavioral Medicine, 35, 581-590.

Gerrard, M., Stock, M. L., Roberts, M. E., Gibbons, F. X., O'hara, R. E., Weng, C. Y., \& Wills, T. A. (2012). Coping with racial discrimination: the role of substance use. Psychology of Addictive Behaviors, 26, 550-560.

Geronimus, A. T., Hicken, M., Keene, D., \& Bound, J. (2006). "Weathering” and age patterns of allostatic load scores among blacks and whites in the United States. American Journal of Public Health, 96, 826-833.

Gibbons, F. X., Etcheverry, P. E., Stock, M. L., Gerrard, M., Weng, C. Y., Kiviniemi, M., \& O'hara, R. E. (2010). Exploring the link between racial discrimination and substance use: What mediates? What buffers?. Journal of personality and social psychology, 99, 785-801.

Gibbons, F. X., O'hara, R. E., Stock, M. L., Gerrard, M., Weng, C. Y., \& Wills, T. A. (2012). The erosive effects of racism: Reduced self-control mediates the relation between perceived racial discrimination and substance use in African American adolescents. Journal of Personality and Social Psychology, 102, 1089-1104.

Gravetter, F. J., \& Wallnau, L. B. (2014). Introduction to the t statistic. Essentials of Statistics for the Behavioral Sciences, 8, 252-.

Greeley, J., \& Oei, T. (1999). Alcohol and tension reduction. Psychological theories of drinking and alcoholism, 2, 14-53.

Harrell, S. P. (2000). A multidimensional conceptualization of racism-related stress: Implications for the well-being of people of color. American Journal of Orthopsychiatry, 70, 42-57. 
Ho, A. K., \& Sidanius, J. (2010). Preserving positive identities: Public and private regard for one's ingroup and susceptibility to stereotype threat. Group Processes \& Intergroup Relations, 13, 55-67.

Hoggard, L. S., Byrd, C. M., \& Sellers, R. M. (2015). The lagged effects of racial discrimination on depressive symptomology and interactions with racial identity. Journal of Counseling Psychology, 62, 216-225.

Humara, M. J., \& Sherman, M. F. (1999). Brief report situational determinants of alcohol abuse among Caucasian and African-American college students. Addictive Behaviors, 24, 135-138.

Hurd, N. M., Varner, F. A., Caldwell, C. H., \& Zimmerman, M. A. (2014). Does perceived racial discrimination predict changes in psychological distress and substance use over time? An examination among Black emerging adults. Developmental Psychology, 50, 1910-1918.

Jones, J. M. (2003). TRIOS: A psychological theory of the African legacy in America. Journal of Social Issues, 59, 217-242.

Joseph, J., \& Kuo, B. C. (2009). Black Canadians' coping responses to racial discrimination. Journal of Black Psychology, 35, 78-101.

Kerr, W. C., Patterson, D., \& Greenfield, T. K. (2009). Differences in the measured alcohol content of drinks between black, white and Hispanic men and women in a US national sample. Addiction, 104, 1503-11.

Kort, D. N. (2017). We Can't Breathe: Affective and Psychophysiological Reactivity of Vicarious Discrimination (Master's thesis).

Kwate, N. O. A., \& Goodman, M. S. (2015). Racism at the intersections: Gender and socioeconomic differences in the experience of racism among African Americans. American Journal of Orthopsychiatry, 85, 397-408. 
Lamis, D. A., \& Lester, D. (2012). Risk factors for suicidal ideation among African American and European American college women. Psychology of Women Quarterly, 36, 337-349.

Landrine, H., \& Klonoff, E. A. (1996). The schedule of racist events: A measure of racial discrimination and a study of its negative physical and mental health consequences. Journal of Black Psychology, 22, 144-168.

Lenhard, W. \& Lenhard, A. (2016). Calculation of Effect Sizes. Retrieved from: https://www.psychometrica.de/effect_size.html. Dettelbach (Germany): Psychometrica. DOI: 10.13140/RG.2.1.3478.4245

MacKillop, J., Miranda Jr, R., Monti, P. M., Ray, L. A., Murphy, J. G., Rohsenow, D. J., ... \& Gwaltney, C. J. (2010). Alcohol demand, delayed reward discounting, and craving in relation to drinking and alcohol use disorders. Journal of Abnormal Psychology, 119, 106-114.

Madkour, A. S., Jackson, K., Wang, H., Miles, T. T., Mather, F., \& Shankar, A. (2015). Perceived discrimination and heavy episodic drinking among African-American youth: Differences by age and reason for discrimination. Journal of Adolescent Health, 57, $530-536$.

Mason, T., Maduro, R., Derlega, V., Hacker, D., Winstead, B., \& Haywood, J. (2016). Individual differences in the impact of vicarious racism: African American students react to the George Zimmerman trial. Cultural Diversity \& Ethnic Minority Psychology, 23, 174-184. doi:10.1037/cdp0000099

McCoy, S. K., \& Major, B. (2003). Group identification moderates emotional responses to perceived prejudice. Personality and Social Psychology Bulletin, 29, 1005-1017.

Neblett, E. W., Jr., Shelton, J. N., \& Sellers, R. M. (2004). The Role of Racial Identity in Managing Daily Racial Hassles. In G. Philogène (Ed.), Decade of behavior. Racial 
identity in context: The legacy of Kenneth B. Clark (pp. 77-90). Washington, DC, US: American Psychological Association.

Nuru-Jeter, A., Dominguez, T. P., Hammond, W. P., Leu, J., Skaff, M., Egerter, S., ... \& Braveman, P. (2009). "It's the skin you're in": African-American women talk about their experiences of racism. An exploratory study to develop measures of racism for birth outcome studies. Maternal and Child Health Journal, 13, 29-39.

O’hara, R. E., Armeli, S., Scott, D. M., Covault, J., \& Tennen, H. (2015). Perceived racial discrimination and negative-mood-related drinking among African American college students. Journal of Studies on Alcohol and Drugs, 76, 229-236.

Operario, D., \& Fiske, S. T. (2001). Ethnic identity moderates perceptions of prejudice: Judgments of personal versus group discrimination and subtle versus blatant bias. Personality and Social Psychology Bulletin, 27, 550-561.

Oyserman, D., Gant, L., \& Ager, J. (1995). A socially contextualized model of African American identity: Possible selves and school persistence. Journal of Personality and Social Psychology, 69, 1216-1232.

Paradies, Y. (2006). A systematic review of empirical research on self-reported racism and health. International Journal of Epidemiology, 35, 888-901.

Pieterse, A. L., Todd, N. R., Neville, H. A., \& Carter, R. T. (2012). Perceived racism and mental health among Alack American adults: A meta-analytic review. Journal of Counseling Psychology, 59, 1-9.

Ramirez, J. J., Monti, P. M., \& Colwill, R. M. (2015). Brief and extended alcohol-cueexposure effects on craving and attentional bias. Experimental and Clinical Psychopharmacology, 23, 159-167.

Rankine, C. (2015, June 22). The condition of Black life is one of mourning. The New York Times. Retrieved from http://www.nytimes .com/2015/06/22/magazine/the-condition- 
of-black-life-is-one-of- mourning.html

Razali, N. M., \& Wah, Y. B. (2011). Power comparisons of shapiro-wilk, kolmogorovsmirnov, lilliefors and anderson-darling tests. Journal of statistical modeling and analytics, 2, 21-33.

Respress, B. N., Small, E., Francis, S. A., \& Cordova, D. (2013). The role of perceived peer prejudice and teacher discrimination on adolescent substance use: A social determinants approach. Journal of Ethnicity in Substance Abuse, 12, 279-299.

Reynolds, W. M. (1982). Development of reliable and valid short forms of the MarloweCrowne Social Desirability Scale. Journal of Clinical Psychology, 38, 119-125.

Richman, L. S., Boynton, M. H., Costanzo, P., \& Banas, K. (2013). Interactive effects of discrimination and racial identity on alcohol-related thoughts and use. Basic and Applied Social Psychology, 35, 396-407.

Salvatore, J., \& Shelton, J. N. (2007). Cognitive costs of exposure to racial prejudice. Psychological Science, 18, 810-815.

Sellers, R. M., Caldwell, C. H., Schmeelk-Cone, K. H., \& Zimmerman, M. A. (2003). Racial identity, racial discrimination, perceived stress, and psychological distress among African American young adults. Journal of Health and Social Behavior, 302-317.

Sellers, R. M., Copeland-Linder, N., Martin, P. P., \& Lewis, R. L. H. (2006). Racial identity matters: The relationship between racial discrimination and psychological functioning in African American adolescents. Journal of Research on Adolescence, 16, 187-216.

Sellers, R. M., \& Shelton, J. N. (2003). The role of racial identity in perceived racial discrimination. Journal of Personality and Social Psychology, 84, 1079-1092.

Sellers, R. M., Smith, M. A., Shelton, J. N., Rowley, S. A., \& Chavous, T. M. (1998). Multidimensional model of racial identity: A reconceptualization of African American racial identity. Personality and Social Psychology Review, 2, 18-39. 
Sinha, R., \& O'Malley, S. S. (1999). Craving for alcohol: findings from the clinic and the laboratory. Alcohol and Alcoholism, 34, 223-230.

Skinner, M. D., \& Aubin, H. J. (2010). Craving's place in addiction theory: contributions of the major models. Neuroscience \& Biobehavioral Reviews, 34, 606-623.

Sobell, L. C., \& Sobell, M. B. (1992). Timeline follow-back. In Measuring alcohol consumption (pp. 41-72). Humana Press.

Sobell, M. B., Sobell, L. C., Klajner, F., Pavan, D., \& Basian, E. (1986). The reliability of a timeline method for assessing normal drinker college students' recent drinking history: Utility for alcohol research. Addictive Behaviors, 11, 149-161.

Stock, M. L., Gibbons, F. X., Gerrard, M., Houlihan, A. E., Weng, C. Y., Lorenz, F. O., \& Simons, R. L. (2013). Racial identification, racial composition, and substance use vulnerability among African American adolescents and young adults. Health Psychology, 32, 237-247.

Stock, M. L., Gibbons, F. X., Walsh, L. A., \& Gerrard, M. (2011). Racial identification, racial discrimination, and substance use vulnerability among African American young adults. Personality and Social Psychology Bulletin, 37, 1349-1361.

Thompson, A. B., Goodman, M. S., \& Kwate, N. O. (2016). Does learning about race prevent substance abuse? Racial discrimination, racial socialization and substance use among African Americans. Addictive Behaviors, 61, 1-7.

Thompson, K., Stockwell, T., Leadbeater, B., \& Homel, J. (2014). Association among different measures of alcohol use across adolescence and emerging adulthood. Addiction, 109, 894-903.

Townshend, J., \& Duka, T. (2001). Attentional bias associated with alcohol cues: differences between heavy and occasional social drinkers. Psychopharmacology, 157, 67-74.

Trochim, W., \& Donnelly, J. P. (2006). The research methods data base. Retrieved July. 
Waelde, L. C., Pennington, D., Mahan, C., Mahan, R., Kabour, M., \& Marquett, R. (2010). Psychometric properties of the Race-Related Events Scale. Psychological Trauma: Theory, Research, Practice, and Policy, 2, 4-11.

Wapp, M., Burren, Y., Znoj, H., \& Moggi, F. (2015). Association of alcohol craving and proximal outcomes of a residential treatment program for patients with alcohol use disorders. Journal of Substance Use, 20, 11-15.

Watson, D., Clark, L. A., \& Tellegen, A. (1988). Development and validation of brief measures of positive and negative affect: The PANAS scales. Journal of Personality and Social Psychology, 54, 1063-1070.

White-Johnson, R. L. (2012). Prosocial involvement among African American young adults: Considering racial discrimination and racial identity. Journal of Black Psychology, 38, 313-341.

Whitfield, K. E., Allaire, J. C., Belue, R., \& Edwards, C. L. (2008). Are comparisons the answer to understanding behavioral aspects of aging in racial and ethnic groups?. The Journals of Gerontology Series B: Psychological Sciences and Social Sciences, 63, P301-P308.

Williams, D. R., \& Mohammed, S. A. (2009). Discrimination and racial disparities in health: evidence and needed research. Journal of Behavioral Medicine, 32, 20-47.

Witbrodt, J., Mulia, N., Zemore, S. E., \& Kerr, W. C. (2014). Racial/ethnic disparities in alcohol-related problems: Differences by gender and level of heavy drinking. Alcoholism: Clinical and Experimental Research, 38, 1662-1670.

Yip, T., Gee, G. C., \& Takeuchi, D. T. (2008). Racial discrimination and psychological distress: The impact of ethnic identity and age among immigrant and United Statesborn Asian adults. Developmental Psychology, 44, 787-800. 
Zapolski, T. C., Pedersen, S. L., McCarthy, D. M., \& Smith, G. T. (2014). Less drinking, yet more problems: Understanding African American drinking and related problems. Psychological Bulletin, 140, 188-223.

Zemore, S. E., Karriker-Jaffe, K. J., Keithly, S., \& Mulia, N. (2011). Racial prejudice and unfair treatment: Interactive effects with poverty and foreign nativity on problem drinking. Journal of Studies on Alcohol and Drugs, 72, 361-370.

Zemore, S. E., Ye, Y., Mulia, N., Martinez, P., Jones-Webb, R., \& Karriker-Jaffe, K. (2016). Poor, persecuted, young, and alone: toward explaining the elevated risk of alcohol problems among Black and Latino men who drink. Drug and Alcohol Dependence, 163, 31-39. 


\section{JESSICA M. DESALU}

7 Quincy Pl NE, Washington DC 20002

Jessica.Desalu@gmail.com; 347.570.7801

\section{Education}

Doctor of Philosophy Candidate, Clinical Psychology

2013-Present

Syracuse University, Syracuse, NY (APA accredited)

Dissertation Title: Vicarious racial discrimination, racial identity, and alcohol-related outcomes among Black young adults: An experimental approach

Advisor: Aesoon Park, Ph.D.

\section{Master of Science, Clinical Psychology}

Syracuse University, Syracuse, NY

Thesis Title: Associations of alcohol-facilitating and stressful environments with alcohol behaviors in Black college students: Moderation by ADH1B*3 and religiosity

Advisor: Aesoon Park, Ph.D.

Bachelor of Science, Psychology

2013

Howard University, Washington, D.C.

\section{Honors AND Awards}

Women in Science and Engineering (WiSE) Student Merit Award (\$400)

2017

Travel Grant, Department of Psychology, Syracuse University $(\$ 1,750)$

Research Society on Alcoholism Student Merit Award (\$575)

Travel Grant, Graduate School, Syracuse University $(\$ 1,330)$

African American Studies Graduate Fellowship, Syracuse University

2013-2014

\section{Clinical Interests}

- Culturally sensitive evidence based treatments

- Assessment and treatment of a range of psychopathology, particularly among underserved populations (e.g., racial minorities, LGBTQ communities)

\section{Clinical Experience}

Pre-Doctoral Clinical Intern

2018-Present

Howard University Counseling Services, Howard University (APA accredited)

- Setting: University Counseling Center 
- Additional rotations at hospital psychiatric inpatient unit and juvenile court of D.C. Superior Court

- Population: Emerging and young adult college students; adults; adolescents all with diverse psychiatric conditions

- Duties: Conduct intake interviews to assess presenting problems and provide recommendations for treatment; provide short and long-term individual psychotherapy services using various theoretical orientations (e.g., psychodynamic, CBT, clientcentered, integrative); conduct psychological assessments

- Individual Therapy Supervisors: Stacey Jackson-Lampley, Ph.D., Marcus Hummings, Ph.D., Victoria Lee, Ph.D., Ekwenzi Gray, Ph.D.

- Assessment Supervisor: Michael Barnes, Ph.D.

- Commitment: Full time employment

\section{Group Co-Facilitator}

2018-Present

LGBTQ Counseling Group, Howard University

- Setting: University counseling center

- Population: College students

- Duties: Co-facilitate a 10-week counseling group focused on discussing and exploring various aspects of being a member of the LGBTQ community

- Supervisor: Ayana Watkins-Northern, Ph.D.

- Commitment: 3 hours per week

Doctoral Student Therapist

2015-2018

Psychological Services Center, Syracuse University

- Setting: University-based outpatient training facility

- Population: Adolescents and adults with diverse psychiatric conditions

- Duties: Conduct intake interviews to assess presenting problems and provide recommendations for treatment; provide weekly individual psychotherapy services using various theoretical orientations (e.g., psychodynamic, CBT, behavioral activation, clientcentered, integrative); conduct psychological/neuropsychological assessments

- Individual Therapy Supervisors: Nina Stoeckel, Ph.D., Amy Cambareri, Ph.D., Leslie Gellis, Ph.D. Sarah Felver, Ph.D., Joseph Himmelsbach, Ph.D., Deborah Pollack, Ph.D., Shannon Sweeney, Ph.D., Allison He, Ph.D.

- Assessment Supervisors: Amy Cambareri, Ph.D., Kevin Antshel, Ph.D., Jessica CostosaUmina, Ph.D., Larry Lewandowski, Ph.D., Sarah Felver, Ph.D., Whitney Wood, Ph.D., Allison He, Ph.D.

- Commitment: 10-20 hours per week

Group Facilitator 2017-2018

\section{Group Co-Facilitator}

2015

Social Skills Training group, Syracuse University

- Setting: University-based outpatient training facility 
- Population: Children with autism spectrum disorder age 7-12

- Duties: Facilitate a 10-week CBT intervention focused on improving communication, social problem solving and emotion regulation skills

- Supervisor: Kevin Antshel, Ph.D.

- Commitment: 2 hours per week

Residential Program Clinician Intern

2016-2017

Elmcrest Children's Center, Syracuse, NY

- Setting: Residential treatment center for children and adolescents; critical care cottage (i.e., residential unit specifically for adolescents with complex needs, history of behavioral disturbances, intense conflict at home, etc.)

- Population: High-risk children and adolescents with a trauma history presenting with multiple externalizing/internalizing concerns

- Role: Provide weekly individual psychotherapy services, as well as supportive/milieu psychotherapy as needed; develop and co-facilitate group therapy curriculum; attend biweekly multidisciplinary team meetings; attend court hearings as needed

- Supervisor: Leah Phaneuf, Ph.D.

- Commitment: 8 hours per week

\section{Service}

Supervised Ad Hoc Reviewer for Ethnicity and Health

2019

Howard University Women's Workshop Outreach Coordinator

2019

Central New York Psychological Association, Events programming

2017-2018

Syracuse University WiSE Women of Color (WoC), Graduate mentor

2016-2018

Supervised Ad Hoc Reviewer for Substance Use and Misuse

2015

Syracuse University Black Graduate Student Association, President

2014-2016

\section{Teaching Experience}

Statistical Methods II, Teaching Assistant

2014-2015; 2016-2017

Syracuse University

- Duties: led weekly lab sessions guiding students to conduct statistical analyses in SPSS and summarize results in APA style writing; review key lecture concepts; assess weekly assignments; hold weekly office hours

\section{Abnormal Psychology, Undergraduate Instructor}

2018

Syracuse University

- Duties: led weekly lectures and discussions regarding a broad range of topics related to abnormal psychology; assess student understanding via examinations and assignments (e.g., case conceptualization); hold weekly office hours 
- Duties: co-led lectures covering a wide range of basic principles in the provision of psychotherapeutic interventions; co-led practices of interventions though active class participation, case vignettes, case conceptualizations, role playing, and some assigned readings; hold weekly office hours

\section{RESEARCH INTERESTS}

- Etiologies of alcohol use and alcohol-related problems amongst individuals of African descent

- Race-related (i.e., racial discrimination) antecedents of alcohol use and risky behaviors in racial minority populations

Dissertation Research

\section{RESEARCH EXPERIENCE}

Department of Psychology, Syracuse University, Syracuse, NY

2017-2019

Advisor: Aesoon Park, Ph.D.

- Investigation of the impact of vicarious racial discrimination on alcohol-related behaviors and cognitions among Black young adults, using an experimental design. Investigation of the extent to which culturally relevant psychosocial factors (e.g., racial identity) attenuate the association.

- Original data collection; original recruited participants, administered survey materials, administered experimental procedures

Qualifying Exam

Department of Psychology, Syracuse University, Syracuse, NY

Advisor: Aesoon Park, Ph.D.

- Meta-analytic review of the association between racial discrimination and alcohol use and related consequences among Black individuals.

\section{Graduate Research Assistant}

Department of Psychology, Syracuse University, Syracuse, NY

Advisor: Aesoon Park, Ph.D.

- Served as a research assistant on a project funded by the National Institute of Health: Person-environment interplay in alcohol use and consequences among urban high school students

- Attended bi-weekly lab meetings to assist with diverse stages of project development

- Assisted with data collection

Masters Thesis Research

2015-2016

Department of Psychology, Syracuse University, Syracuse, NY

Advisor: Aesoon Park, Ph.D.

- Examined protective effects of the $A D H 1 B * 3$ allele, an alcohol metabolizing gene found almost exclusively in Blacks, and religiosity on the relationship between risky 
environments and alcohol behaviors among Black college students.

- Original data collection; recruited participants, administered survey materials, and conducted saliva sample procedures for genotyping analyses

\section{Publications}

Desalu, J. M., Goodhines, P. A., \& Park, A. (2019). Racial Discrimination and Alcohol Use and Negative Drinking Consequences among Black Americans: A Meta-Analytic Review. Addiction. Advance online publication. doi: https://doi.org/10.1111/add.14578

Zaso, M. J., Desalu, J. M., Kim, J., Suryadevara, K., Belote, J. M., \& Park, A. (2018). Interaction between the ADH1B* 3 allele and drinking motives on alcohol use among Black college students. The American Journal of Drug and Alcohol Abuse, 44, 329338.

Desalu, J. M., Zaso, M. J., Kim, J., Belote, J. M., \& Park, A. (2017). Interaction between ADH1B* 3 and alcohol-facilitating social environments in alcohol behaviors among college students of African descent. The American Journal on Addictions, 26, 349356.

Desalu, J. M., Kim, J., Zaso, M. J., Corriders, S. R., Loury, J. A., Minter, M. L., \& Park, A. (2017). Racial discrimination, binge drinking, and negative drinking consequences among black college students: serial mediation by depressive symptoms and coping motives. Ethnicity \& Health, 21,1-15.

\section{Presentations}

*Asterisk denotes undergraduate student mentee

Goodhines, P. A., Desalu, J. M., Zaso, M. J., Gellis, L. A., \& Park, A. (2019, June). Sleep problems and binge drinking among urban multiracial and monoracial youth: Role of discrimination experiences and negative mood. Poster to be presented at the 33nd annual meeting of the American Professional Sleep Societies (SLEEP), San Antonio, TX.

Desalu, J. M., \& Park, A. (2017, June). Racial differences in urban adolescent risky health behaviors: Moderation by perceived peer norms. Poster presented at the 40th Annual Research Society on Alcoholism Scientific Meeting, Denver, CO.

Desalu, J. M., Zaso, M. J., Kim, J., \& Park, A. (2016, June). The influence of ADH1B*3 and socio-environmental factors on alcohol outcomes in Black college students. Poster presented at the 39th Annual Research Society on Alcoholism Scientific Meeting, New Orleans, LA.

Zaso, M. J., *Suryadevara, K., Desalu, J. M., Kim, J., \& Park, A. (2016, June). Interaction between the ADHIB*3 allele and drinking motives on alcohol use among Black college students. Poster presented at the 39th Annual Research Society on Alcoholism Scientific Meeting, New Orleans, LA. 
Zaso, M. J., Park, A., Kim, J., Desalu, J. M., \& Kwon, H. (2015, August). Alcohol-related consequences and future drinking: The role of experience and subjective evaluations. Oral presentation at the 123rd Annual Convention of the American Psychological Association, Toronto, ON.

Desalu, J. M., *Corriders, S. R., Zaso, M. J., Kim, J., \& Park, A. (2014, July).

Discrimination, alcohol use, \& drinking consequences in Black college students. Poster presented at the annual meeting of the Association of Black Psychologists, Indianapolis, IN.

Desalu, J. M., *Corriders, S. R., Zaso, M. J., Kim, J., \& Park, A. (2014, June). Racial discrimination, alcohol use, and negative drinking consequences among Black college students. Poster presented at the annual meeting of the Research Society on Alcoholism, Bellevue, WA.

\section{Undergraduate Research Mentorship}

Najheri Salley (nominee for outstanding research award);

2017-2018

Shyanne Ninham; Ritozeh Saingbe

Brittany Stuart (recipient of undergraduate research grant, \$500)

2015-2016

Andra Brown; Jacoby Loury (recipient of undergraduate research grant, \$500); 2014-2015 Taiwo Majekdunmi; Keturah Williams

Sydnee Corriders (recipient of undergraduate research grant, \$500);

Sharde McLeish; Monique Minter; Kaitlyn Williams

\section{Statistical Skills}

\section{$\underline{\text { Software Experience }}$}

SPSS, Mplus (for structural equation modeling), Comprehensive Meta-Analysis

\section{$\underline{\text { Advanced Statistical Coursework }}$}

Introduction to Structural Equation Modeling

2014

Semester-long course taught by Aesoon Park, Ph.D.

Syracuse University

\section{Professional Affiliates}

Central New York Psychological Association

2017-2018

Women in Science and Engineering (WiSE), Syracuse University

2014-2016

American Psychological Association, Division 38 (Health Psychology)

2014-Present

Research Society on Alcoholism

2014-Present

Association of Black Psychologists

2013-Present 